ano 14 - n. 58 | outubro/dezembro - 2014

Belo Horizonte I p. 1-296 I ISSN 1516-3210

A\&C - R. de Dir. Administrativo \& Constitucional

Revista de Direito ADMINISTRATIVO \& CONSTITUCIONAL

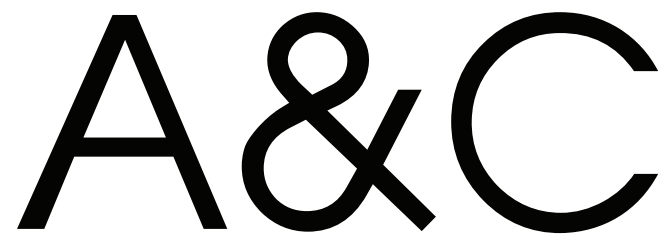


A\&C - REVISTA DE DIREITO ADMINISTRATIVO \& CONSTITUCIONAL

\section{IPDA}

Instituto Paranaense

de Direito Administrativo
ROMEU FELPE

BACELLAR

() 2014 Editora Fórum Ltda.

Todos os direitos reservados. É proibida a reprodução total ou parcial, de qualquer forma ou por qualquer meio eletrônico ou mecânico, inclusive através de processos xerográficos, de fotocópias ou de gravação, sem permissão por escrito do possuidor dos direitos de cópias (Lei no 9.610, de 19.02.1998)

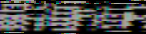

Luís Cláudio Rodrigues Ferreira

Presidente e Editor

Av. Afonso Pena, 2770 - 16² andar - Funcionários - CEP 30130-007 - Belo Horizonte/MG - Brasil - Tel.: 08007043737 www.editoraforum.com.br / E-mail: editoraforum@editoraforum.com.br

Impressa no Brasil / Printed in Brazil / Distribuída em todo o Território Nacional

Os conceitos e opiniões expressas nos trabalhos assinados são de responsabilidade exclusiva de seus autores.

A246 A\&C : Revista de Direito Administrativo \&
Constitucional. - ano 3, n. 11, jan./mar.
2003)- . - Belo Horizonte: Fórum, 2003-
Trimestral
ISSN: 1516-3210
Ano 1, n. 1, 1999 até ano 2, n. 10, 2002 publicada
pela Editora Juruá em Curitiba
$\begin{aligned} & \text { 1. Direito administrativo. 2. Direito constitucional. } \\ & \text { I. Fórum. } \\ & \text { CDD: } 342 \\ & \text { CDU: } 342.9\end{aligned}$

Supervisão editorial: Leonardo Eustáquio Siqueira Araújo

Revisão: Lourdes Nascimento

Capa: Igor Jamur

Projeto gráfico: Walter Santos

Diagramação: Bruno Lopes

Periódico classificado no Estrato B1 do Sistema Qualis da CAPES - Área: Direito.

Revista do Programa de Pós-graduação do Instituto de Direito Romeu Felipe Bacellar (Instituição de Pesquisa e Pós-Graduação), em convênio com o Instituto Paranaense de Direito Administrativo (entidade associativa de âmbito regional filiada ao Instituto Brasileiro de Direito Administrativo). A linha editorial da $A \& C$ - Revista de Direito Administrativo \& Constitucional segue as diretrizes do Programa de Pós-Graduação do Instituto de Direito Romeu Felipe Bacellar em convênio com o Instituto Paranaense de Direito Administrativo. Procura divulgar as pesquisas desenvolvidas na área de Direito Constitucional e de Direito Administrativo, com foco na questão da efetividade dos seus institutos não só no Brasil como no direito comparado, com ênfase na questão da interação e efetividade dos seus institutos, notadamente América Latina e países europeus de cultura latina.

A publicação é decidida com base em pareceres, respeitando-se o anonimato tanto do autor quanto dos pareceristas (sistema double-blind peer review).

Desde o primeiro número da Revista, $75 \%$ dos artigos publicados (por volume anual) são de autores vinculados a pelo menos cinco instituições distintas do Instituto de Direito Romeu Felipe Bacellar.

A partir do volume referente ao ano de 2008 , pelo menos $15 \%$ dos artigos publicados são de autores filiados a instituições estrangeiras.

Esta publicação está catalogada em:

- Ulrich's Periodicals Directory

- RVBI (Rede Virtual de Bibliotecas - Congresso Nacional)

- Library of Congress (Biblioteca do Congresso dos EUA)

A\&C - Revista de Direito Administrativo \& Constitucional realiza permuta com as seguintes publicações:

- Revista da Faculdade de Direito, Universidade de São Paulo (USP), ISSN 0303-9838

- Rivista Diritto Pubblico Comparato ed Europeo, ISBN/EAN 978-88-348-9934-2 
Diretor-Geral

Romeu Felipe Bacellar Filho

Diretor Editorial

Paulo Roberto Ferreira Motta

Editores Acadêmicos Responsáveis

Daniel Wunder Hachem

Ana Cláudia Finger

\section{Conselho Editorial}

Adilson Abreu Dallari (PUC-SP) Adriana da Costa Ricardo Schier (Instituto Bacellar) Alice Gonzalez Borges (UFBA) Carlos Ari Sundfeld (FGV-SP) Carlos Delpiazzo (Universidad de La República - Uruguai) Cármen Lúcia Antunes Rocha (PUC Minas) Célio Heitor Guimarães (Instituto Bacellar) Celso Antônio Bandeira de Mello (PUC-SP) Clèmerson Merlin Clève (UFPR) Clovis Beznos (PUC-SP) Edgar Chiuratto Guimarães (Instituto Bacellar) Emerson Gabardo (UFPR) Enrique Silva Cimma (Universidad de Chile - Chile)
Eros Roberto Grau (USP) Irmgard Elena Lepenies (Universidad Nacional del Litoral - Argentina) Jaime Rodríguez-Arana Muñoz (Universidad de La Coruña - Espanha) José Carlos Abraão (UEL) José Eduardo Martins Cardoso (PUC-SP) José Luís Said (Universidad de Buenos Aires - Argentina) José Mario Serrate Paz (Universidad de Santa Cruz - Bolívia)

Justo J. Reyna (Universidad Nacional del Litoral - Argentina) Juarez Freitas (UFRGS) Luís Enrique Chase Plate (Universidad Nacional de Asunción - Paragual) Marçal Justen Filho (UFPR) Marcelo Figueiredo (PUC-SP)

Márcio Cammarosano (PUC-SP)

Maria Cristina Cesar de Oliveira (UFPA)

Nelson Figueiredo (UFG)

Odilon Borges Junior (UFES)

Pascual Caiella (Universidad de La Plata - Argentina)

Paulo Eduardo Garrido Modesto (UFBA)

Paulo Henrique Blasi (UFSC)

Pedro Paulo de Almeida Dutra (UFMG)

Regina Maria Macedo Nery Ferrari (UFPR)

Rogério Gesta Leal (UNISC)

Rolando Pantoja Bauzá (Universidad Nacional de Chile - Chile)

Sergio Ferraz (PUC-Rio)

Valmir Pontes Filho (UFCE)

Weida Zancaner (PUC-SP)

Yara Stroppa (PUC-SP)

Juan Pablo Cajarville Peluffo (Universidad de La República - Uruguai)

Homenagem Especial

Guillermo Andrés Muñoz (in memoriam)

Jorge Luís Salomoni (in memoriam)

Julio Rodolfo Comadira (in memoriam)

Lúcia Valle Figueiredo (in memoriam)

Manoel de Oliveira Franco Sobrinho (in memoriam)

Paulo Neves de Carvalho (in memoriam) 


\title{
La transparencia como política pública contra la corrupción: aportes sobre la regulación de derecho de acceso a la información pública
}

\begin{abstract}
Alfonso Buteler
Abogado (Facultad de Derecho y Ciencias Sociales de la Universidad Nacional de Córdoba, Argentina) Premio Cuadro de Honor a los mejores promedios, Magister Derecho Administrativo (Universidad Austral) Doctor en Derecho y Ciencias Sociales (UNC). Docente de Derecho Administrativo (Facultad de Derecho, UNC) y de Derecho Procesal Público (Universidad Empresarial Siglo 21), Miembro del Instituto de Derecho Administrativo de la Facultad de Derecho y Ciencias Sociales (UNC), Miembro del Instituto de Derecho Administrativo de la Escuela de Derecho de la (UES21) Autor de un libro y de numerosas publicaciones en obras colectivas y revistas especializadas sobre la materia.
\end{abstract}

Resumen: El presente trabajo tiene por objeto analizar la vinculación entre la corrupción, la transparencia y poner de resalto los principales lineamientos que debe tener la regulación del acceso a la información pública.

Palabras-clave: Corrupción. Transparencia. Información pública.

Sumario: I Introducción - II Información pública y corrupción - III Aproximación conceptual al DAIP IV Evolución - V Plataforma constitucional - VI La regulación en el plano supranacional - VII La jurisprudencia de la Corte Suprema - VIII Objeto de acceso - IX Principios aplicables - X Titularidad del derecho informativo - XI Legitimación - XII Limitaciones - XIII Mecanismos de protección - XIV La información pública positiva

\section{| Introducción}

El presente trabajo tiene por objeto, en primer término, poner de resalto la estrecha vinculación entre la lucha anticorrupción y las políticas públicas en favor de la transparencia.

En segundo lugar, procuramos destacar el papel que desempeña el sistema de acceso a la información pública como vehículo para conseguir que la administración pública logre dicho cometido.

\section{Información pública y corrupción}

Se ha dicho, con razón, que la transparencia es la otra cara de la moneda de la corrupción. Dado que la regulación del derecho de acceso a la información pública 
aparece como una herramienta para que el Estado sea visible puertas adentro la vinculación entre dicho derecho y la corrupción resulta innegable.

Tal relación, tiene claras evidencias de carácter concreto dado que los países que poseen leyes de acceso a la información pública tienen un nivel más bajo de corrupción. Así, mientras existen tales como Brasil, ${ }^{1}$ Panamá, Canadá o Uruguay que han dictado leyes de acceso a la información pública, en la República Argentina solo existe el Decreto 1172/03 de aplicación en el ámbito del Poder Ejecutivo Nacional, es decir, que no existe una ley aplicable a todo el Estado federal. Ello, sin perjuicio de otras cuestiones, ha llevado a nuestro país a estar entre los países con mayores niveles de corrupción del mundo ubicándoselo, por lo general, por encima del puesto número cien en nivel de trasparencia. ${ }^{2}$

Esta estrecha ligazón entre acceso a la información y corrupción ha sido puesta de resalto por la Corte Suprema de Justicia de la Nación en un reciente precedente en la causa "CIPPEC" 3 al enmarcar la contienda sobre acceso a la información pública en el marco de la Convención de Naciones Unidas contra la Corrupción, adoptada el 31 de octubre de 2003 y aprobada en la República Argentina por la ley 26.097.4

\section{Aproximación conceptual al DAIP}

El acceso a la información pública constituye un derecho humano fundamental, reconocido en la mayoría de los sistemas jurídicos comparados y supranacionales, por el cual se permite a toda persona acceder a datos, registros, expedientes y a cualquier tipo de información que se encuentre en poder de autoridades públicas o privadas que lleven adelante cometidos públicos.

De esta manera, este instituto se erige dentro del Estado de Derecho en un cauce de participación ciudadana, por cuyo conducto se procura fomentar la transparencia de la actividad estatal y el control del ejercicio del poder público y de la corrupción gubernamental.

Con relación a ello, ha dicho la Corte Suprema que la negativa a brindar la información requerida por una persona constituye un acto arbitrario e ilegítimo en el marco de los principios de una sociedad democrática e implica, en consecuencia,

\footnotetext{
1 Brasil (ley 12.527/2012), Panamá (Ley 6/2002), Canadá (Acces to Information act), Uruguay (Ley 18.381), entre muchos otros.

2 Pueden consultarse los índices de Transparencia Internacional de los últimos años en: www.transparency. org. Se ha señalado desde la doctrina que es relativa la utilidad de esa clasificación "en la medida en que se trata de una percepción interesada de aquellos empresarios que se orientan en función de su reales y posibles negocios, pero creemos que es un indicador que merece su atención ya que surge de quienes posibilitan inversiones que son cada vez más necesarias y requeridas en la región" (PEREZ HUALDE, Alejandro, “Desviación de poder como 'sistema' y un instrumento necesario: las lealtades personales”, Suplemento de derecho Administrativo, La ley, febrero de 2012, no1, p. 4).

3 CS, 26/03/2014, “CIPPEC c. EN M№ DESARROLLO SOCIAL DTO 1172/03”, C. 830. XLVI. REX.

4 Considerando no 11.
} 
una acción que recorta en forma severa derechos que son reservados a cualquier ciudadano, en tanto se trate de datos de indudable interés público y que hagan a la transparencia y a la publicidad de gestión de gobierno, pilares fundamentales de una sociedad que se precie de ser democrática. ${ }^{5}$ Pues, desde la perspectiva de abordaje del Alto Tribunal el fundamento central del acceso a la información en poder del Estado consiste en el derecho que tiene toda persona de conocer la manera en que sus gobernantes y funcionarios públicos se desempeñan. ${ }^{6}$

Cabe destacar, que este derecho, posee un antiguo antecedente en el derecho comparado que se remonta a la Real Ordenanza Sueca sobre la libertad de prensa del año 1766 y, que a partir de entonces, se ha propagado por numerosos países conjuntamente con la democracia entre los que cabe mencionar a España (Art. 105 inc. b de su Constitución), Estados Unidos (Freedom of Information Act de 1966), Francia (Ley del 17 de junio de 1978), Italia (Ley del 7 de agosto de 1990) y la Unión Europea (Art. 42 de la Carta de Derechos Fundamentales). ${ }^{7}$

En el plano federal el dictado del Decreto $1172 / 03^{8}$ vino a cubrir un vacío normativo en la materia al regular lo relativo al acceso a la información pública en el ámbito del Poder Ejecutivo Nacional aunque todavía es una deuda pendiente del Congreso el dictado de una ley que sea aplicable a toda la órbita federal.

\section{Evolución}

\section{a) El modelo de confidencialidad y secreto}

De manera previa a la consagración normativa y constitucional del derecho de acceso a la información pública ${ }^{9}$ era una facultad de la administración pública brindar o no la información solicitada por el particular. Es decir, era el propio Estado el que se consideraba titular de la facultad de decidir si hacía público sus asuntos. Ello, se traducía en un poder inmenso que era poseído por unos $\operatorname{pocos}^{10}$ y que ponía en jaque la idea de la existencia de un verdadero sistema republicano de gobierno.

Ese modelo de sociedad basada en el "oscurantismo" acompañó a los gobiernos desde épocas remotas y se mantuvo vigente con marcada intensidad hasta mediados del Siglo XIX, aproximadamente. Esa situación, implicaba que la información estatal era controlada y monopolizada por el poder de turno siendo utilizada, muchas veces, con fines políticos y estratégicos alejados del bien común.

\footnotetext{
5 C.S.J.N., 04/12/2012, “Asociación Derechos Civiles c. EN - PAMI - (dto.1172/03) s/ amparo ley 16.986”, A. $917 . \mathrm{XLVI}$.

6 CSJN, 26/03/2014, “CIPPEC c/ EN - Ministerio de Desarrollo Social - dto. 1172/03 s/ amparo ley 16.986", causa C.830.XLVI.

7 Cfr. SÁNCHEZ MORON, Miguel, Derecho Administrativo, Madrid, Tecnos, 2007, 3a Ed., p. 454.

8 B.0. 4/12/2003.

9 En adelante utilizaremos la abreviatura DAIP.

10 Cfr. GUICHOT EMILIO, "El nuevo derecho europeo de acceso a la información pública", Revista de la Administración Pública española, № 160 (2003), p. 291.
} 
En esta etapa, el ciudadano que pretendía el conocimiento de los actos estatales, debía acreditar la titularidad de una situación jurídica subjetiva — derecho subjetivo o interés legítimo- que le permitiera ser parte en el procedimiento administrativo, debiendo explicitar las razones que lo llevaba a requerir la información. A su vez, ante la denegación de la misma el interesado quedaba obligado a lograr el agotamiento de la vía administrativa a través de la interposición de los recursos pertinentes contra el acto administrativo denegatorio para recién poder acudir al auxilio del órgano judicial.

\section{b) El reconocimiento del derecho de acceso a la información pública}

El nacimiento de la sociedad de la información y el reconocimiento del DAIP implicó una conquista que ha sido denominada como "histórica" ${ }^{11}$ que, a su vez, derivó en una marcada modificación de la regla general imperante en la etapa anterior según la cual, el funcionamiento administrativo y las relaciones con la administración pública y el ciudadano bajo "secreto".

Es que, en definitiva, se advirtió que la consolidación del Estado Democrático de Derecho dependía, en gran medida, del respeto a ese derecho fundamental y de un sistema republicano basado en la publicidad de los actos de gobierno y justamente, esa circunstancia, es la que motivó que el reconocimiento en la mayoría de los sistemas jurídicos comparados ${ }^{12}$ y supranacionales por los cuales se permite a toda persona acceder a datos, registros, expedientes y a cualquier tipo de información que se encuentre en poder de autoridades públicas o privadas que lleven adelante cometidos públicos, sin aducir las razones para ello.

Así, en la actualidad, la presencia del ciudadano permite la fiscalización de las decisiones públicas y el conocimiento de las mismas evitando, de ese modo, el oscurantismo estatal, posibilitando el control de la corrupción estatal y el desempeño de los funcionarios dentro de los márgenes previstos en la Ley de Ética Pública. ${ }^{13}$ Por tales razones, la Convención Interamericana contra la Corrupción ${ }^{14}$ y la Convención de Naciones Unidas contra la Corrupción ${ }^{15}$ se han hecho eco de la cuestión al imponer a los Estados Partes el deber imperativo de instaurar en los sistemas internos mecanismos que permitan el desenvolvimiento del DAIP.

\footnotetext{
${ }^{11}$ Cfr. SANCHEZ MORON, Miguel, "El derecho de acceso a la información en materia de medioambiente", Revista de Administración Pública española, № 137 (1995), p. 31.

12 Cfr. SÁNCHEZ MORON, M., Derecho administrativo, op. cit. p. 454. Sobre el desarrollo de ese derecho en el sistema comparado puede verse: BASTERRA, Marcela I., El derecho fundamental de acceso a la información pública, Buenos Aires Lexis Nexis, 2006., p. 207 y ss.; TRAVIESO, Florencio, "El derecho de acceso a la información pública. Principios y fundamentos en un reciente fallo", E.D., 197:297.

${ }^{13}$ Ley 25.188, B.0. 01/11/1999.

${ }_{14}$ Aprobada por Ley 24.759, B.0. 19/01/1997.

15 Aprobada por Ley 26.097, B.0., 09/06/06.
} 
En seguimiento de esa tendencia mundial y más allá del reconocimiento constitucional y normativo especifico, en nuestro país se dictó hace unos años el Decreto $1172 / 03^{16}$ que —entre otros aspectos ${ }^{17}$ — vino a regular lo relativo al acceso a la información pública en el ámbito del Poder Ejecutivo Nacional. Dicha norma, dispone en sus considerandos que aquel derecho constituye un "prerrequisito de la participación que permite controlar la corrupción, optimizar la eficiencia de las instancias gubernamentales y mejorar la calidad de vida de las personas al darle a éstas la posibilidad de conocer los contenidos de las decisiones que se toman día a día para ayudar a definir y sustentar lo propósitos para una mejor comunidad".

Es que como lo señaló el juez Fayt al resolver la causa "Verbitsky", ${ }^{18}$ "la información condiciona la existencia y las actividades de cada sociedad y la participación resulta imposible sin ella" a lo que debe sumarse la importancia estratégica de la misma en el diseño de políticas públicas y privadas.

\section{c) La información pública positiva}

Amén de la importancia de lo apuntando precedentemente en cuanto al desarrollo que ha tenido el DAIP en los diversos sistemas, debe destacarse que en la actualidad ya no alcanza con que el Estado permita el acceso de los interesados a la información pública o con que se establezcan herramientas procesales para los casos en que la misma es retaceada, total o parcialmente. Pues, un nuevo concepto se viene abriendo camino desde hace unos años: la información pública positiva. El mismo implica que va a ser a propia administración pública quien por su propia iniciativa o por imposición legal quien deba poner en conocimiento de la ciudadanía a través de su publicación cierta información "mínima" que se considere útil en un sistema democrático y trasparente, ${ }^{19}$ la cual debe ir aumentando gradualmente.

Solo hacemos esta breve referencia a los efectos de poner de resalto las diversas etapas evolutivas del DAIP. Luego, analizaremos esta cuestión con mayor detenimiento.

\section{Plataforma constitucional}

El derecho al acceso a la información pública tiene anclaje constitucional en diversas cláusulas de la Ley Fundamental. En primer término, debemos destacar, el

\footnotetext{
16 B.0. 4/12/2003.

17 También regula lo relativo al régimen de audiencias públicas, el lobby, la participación en la elaboración de normas generales, etc. Sobre ese tema puede consultarse: BRUNO DOS SANTOS, Marcelo A., FERNÁNDEZ LAMELA, Pablo M., y LOPEZ OLVERA, Miguel Alejandro, "La participación pública y el acceso a la información: herramientas para mejorar la calidad institucional. Comentarios al Decreto 1.172/03”, Revista RAP, no 315, p. 91 y ss.

18 L.L. 1989-D, 183.

19 Cfr. GUICHOT, E., op. cit., p. 286.
} 
art. $1^{\circ}$ en cuanto establece el sistema republicano de gobierno e impone la publicidad de los actos públicos.

En segundo, lugar hay que mencionar el art. 38 de la C.N. habida cuenta que brinda apoyatura constitucional en lo relativo a los partidos políticos al exigir que se garantice a los mismos el acceso a la información pública.

En tercer término, también debemos mencionar el art 33 cuando prescribe que "Las declaraciones, derechos y garantías que enumera la Constitución no serán entendidos como negación de otros derechos y garantías no enumerados; pero que nacen del principio de la soberanía del pueblo y de la forma republicana de gobierno". Ello, en tanto, esta disposición constitucional "proporciona fundamento suficiente a la obligación de dar publicidad a todos los actos de gobierno dado que, esa norma, reconoce los derechos que emanan de la soberanía del pueblo". ${ }^{20}$ En tal sentido, se pronunció la Corte Suprema en el caso "Asociación Derechos Civiles". ${ }^{21}$

Por último, el art. 41 luego de consagrar los derechos relativos al medioambiente obliga a las autoridades a proteger el mismo y a la información de carácter ambiental y el art. 42, por otro lado, establece el derecho de los consumidores y de los usuarios de bienes y servicios a una información adecuada y veraz.

\section{La regulación en el plano supranacional}

\section{En contenido de los tratados internacionales}

Los instrumentos internacionales que tienen jerarquía constitucional por intermedio del art. 75 inc. 22 de la Ley Fundamental, contemplan regulaciones del derecho de acceso a la información pública con diversas modalidades y alcances.

La Declaración Universal de Derechos Humanos en el art. 19 dispone que “Todo individuo tiene derecho a la libertad de opinión y de expresión; este derecho incluye el de no ser molestado a causa de sus opiniones, el de investigar y recibir informaciones y opiniones, y el de difundirlas, sin limitación de fronteras, por cualquier medio de expresión".

Por su parte, el Pacto Internacional de Derechos Civiles y Políticos señala que “Toda persona tiene derecho a la libertad de expresión; este derecho comprende la libertad de buscar, recibir y difundir informaciones e ideas de toda índole, sin consideración de fronteras, ya sea oralmente, por escrito o en forma impresa o artística, o por cualquier otro procedimiento de su elección" (Art. 19 inc. 2).

\footnotetext{
20 Cfr. GELLI, María Angélica, Constitución de la Nación Argentina, comentada y concordada, Buenos Aires, La Ley, 2003, 2ª Ed. act. y ampl., p. 22/3.

${ }^{21}$ C.S.J.N., 04/12/2012, “Asociación Derechos Civiles c. EN — PAMI — (dto.1172/03) s/ amparo ley 16.986", A. 917. XLVI, considerando 6‥
} 
A su vez, la Declaración Americana de los Derechos y Deberes del Hombre indica que "Toda persona tiene derecho a la libertad de investigación, de opinión y de expresión y difusión del pensamiento por cualquier medio" (Artículo IV).

Por último, la Convención Americana sobre Derechos Humanos (en adelante $\mathrm{CADH}$ ) en el art. 13 establece que "1. Toda persona tiene derecho a la libertad de pensamiento y de expresión. Este derecho comprende la libertad de buscar, recibir y difundir informaciones e ideas de toda índole, sin consideración de fronteras, ya sea oralmente, por escrito o en forma impresa o artística, o por cualquier otro procedimiento de su elección. 2. El ejercicio del derecho previsto en el inciso precedente no puede estar sujeto a previa censura sino a responsabilidades ulteriores, las que deben estar expresamente fijadas por la ley y ser necesarias para asegurar: a) el respeto a los derechos o a la reputación de los demás, o b) la protección de la seguridad nacional, el orden público o la salud o la moral públicas."

La cuestión que venimos analizando, además, ha sido regulada en el plano internacional por otros instrumentos que no tienen jerarquía constitucional pero si superior a las leyes (art. $31 \mathrm{CN}$ ).

Entre ellas mencionamos a la Convención de Naciones Unidas contra la corrupción, que ha sido ratificada por nuestro país, lo que hace aplicables su contenido debido a su carácter operativo. ${ }^{22}$

Dicho instrumento prevé en el art. 10 que "Habida cuenta de la necesidad de combatir la corrupción, cada Estado Parte, de conformidad con los principios fundamentales de su derecho interno, adoptará las medidas que sean necesarias para aumentar la transparencia en su administración pública, incluso en lo relativo a su organización, funcionamiento y procesos de adopción de decisiones, cuando proceda. Esas medidas podrán incluir, entre otras cosas: a) La instauración de procedimientos o reglamentaciones que permitan al público en general obtener, cuando proceda, información sobre la organización, el funcionamiento y los procesos de adopción de decisiones de su administración pública y, con el debido respeto a la protección de la intimidad y de los datos personales, sobre las decisiones y actos jurídicos que incumban al público; b) La simplificación de los procedimientos administrativos, cuando proceda, a fin de facilitar el acceso del público a las autoridades encargadas de la adopción de decisiones; y c) La publicación de información, lo que podrá incluir informes periódicos sobre los riesgos de corrupción en su administración pública".

Por otra parte, el art. 13 dispone que "Cada Estado Parte adoptará medidas adecuadas, dentro de los medios de que disponga y de conformidad con los principios fundamentales de su derecho interno, para fomentar la participación activa de personas y grupos que no pertenezcan al sector público, como la sociedad civil, las

\footnotetext{
22 Para Manfroni la operatividad no es inmediata en materia penal (MANFRONI, Carlos A., La convención interamericana contra la corrupción, anotada y comentada, Buenos Aires, Abeledo Perrot, 2001, 2ª Ed. act. p. 112).
} 
organizaciones no gubernamentales y las organizaciones con base en la comunidad, en la prevención y la lucha contra la corrupción, y para sensibilizar a la opinión pública con respecto a la existencia, las causas y la gravedad de la corrupción, así como a la amenaza que ésta representa. Esa participación debería reforzarse con medidas como las siguientes: a) Aumentar la transparencia y promover la contribución de la ciudadanía a los procesos de adopción de decisiones; b) Garantizar el acceso eficaz del público a la información; c) Realizar actividades de información pública para fomentar la intransigencia con la corrupción, así como programas de educación pública, incluidos programas escolares y universitarios; d) Respetar, promover y proteger la libertad de buscar, recibir, publicar y difundir información relativa a la corrupción".

\section{La Declaración de principios sobre libertad de expresión de la Comisión Interamericana de Derechos Humanos ${ }^{23}$}

En la referida declaración la Comisión Interamericana dejó sentado los siguientes principios:

a) La libertad de expresión es un derecho fundamental e inalienable, inherente a todas las personas y un requisito indispensable para la existencia misma de una sociedad democrática.

b) Toda persona tiene el derecho a buscar, recibir y difundir información y opiniones libremente y deben contar con igualdad de oportunidades para recibir, buscar e impartir información por cualquier medio de comunicación sin discriminación.

c) Toda persona tiene el derecho a acceder a la información sobre sí misma o sus bienes en forma expedita y no onerosa, ya esté contenida en bases de datos, registros públicos o privados y, en el caso de que fuere necesario, actualizarla, rectificarla y/o enmendarla.

d) El acceso a la información en poder del Estado es un derecho fundamental de los individuos que debe ser garantizado en su ejercicio por el Estado.

e) Dicho derecho solo puede ser limitado mediante excepciones establecidas por ley para el caso que exista un peligro real e inminente que amenace la seguridad nacional en sociedades democráticas.

f) La censura previa, interferencia o presión directa o indirecta sobre cualquier expresión, opinión o información difundida a través de cualquier medio de comunicación oral, escrito, artístico, visual o electrónico, debe estar prohibida por la ley. Las restricciones en la circulación libre de ideas y

\footnotetext{
${ }^{23}$ Aprobada en octubre del año 2000.
} 
opiniones, como así también la imposición arbitraria de información y la creación de obstáculos al libre flujo informativo, violan el derecho a la libertad de expresión.

g) Toda persona tiene derecho a comunicar sus opiniones por cualquier medio y forma. La colegiación obligatoria o la exigencia de títulos para el ejercicio de la actividad periodística, constituyen una restricción ilegítima a la libertad de expresión.

h) Las leyes de privacidad no deben ser utilizadas para restringir la investigación y difusión de información de interés público. La protección a la reputación debe estar garantizada sólo a través de sanciones civiles, en los casos en que la persona ofendida sea un funcionario público o persona pública o particular que se haya involucrado voluntariamente en asuntos de interés público.

i) Los funcionarios públicos están sujetos a un mayor escrutinio por parte de la sociedad. Las leyes que penalizan la expresión ofensiva dirigida a funcionarios públicos generalmente conocidas como "leyes de desacato" atentan contra la libertad de expresión y el derecho a la información.

\section{El criterio de la Corte Interamericana de Derechos Humanos ${ }^{24}$}

Preliminarmente, antes de ingresar en el análisis de los criterios sobre la cuestión del acceso a la información es importante dejar sentado que la CIDH toma como base de tal derecho a la libertad de pensamiento y de opinión.

\section{La Opinión Consultiva $5 / 85^{25}$}

Esta intervención de la CIDH tuvo su génesis en un pedido realizado por el gobierno de Costa Rica a raíz de una normativa por la cual se pretendía imponer la colegiación obligatoria de periodistas. Ello a los fines que se determine si la misma respetaba el contenido de los arts. 13 y 29 de la $\mathrm{CADH}$.

Antes de avanzar en su contenido, es muy importante tener en cuenta que en este instrumento la CIDH estableció las bases conceptuales del derecho a la libertad de pensamiento y opinión y dejó en claro la íntima relación entre este derecho y el de acceso a la información; criterio que luego continuó moldeando a través de las numerosas sentencias dictadas en la materia.

En tal sentido, se señaló que el art. 13 de la CADH cuando consagra la libertad de pensamiento y expresión "comprende la libertad de buscar, recibir y difundir

\footnotetext{
${ }^{24}$ En adelante $\mathrm{CIDH}$.

${ }^{25}$ En adelante OC 5/85.
} 
informaciones e ideas de toda índole". Por tal motivo, sostuvo que la Convención ampara tanto el derecho y la libertad de expresar su pensamiento sino también el derecho y la libertad de buscar, recibir y difundir informaciones e ideas de toda índole. Pues, "cuando se restringe ilegalmente la libertad de expresión de un individuo, no sólo es el derecho de ese individuo el que está siendo violado, sino también el derecho de todos a 'recibir' informaciones e ideas, de donde resulta que el derecho protegido por el artículo 13 tiene un alcance y un carácter especiales".

Asimismo, destacó las dos dimensiones que posee la libertad de expresión. Por un lado, existe la exigencia de que nadie sea arbitrariamente menoscabado o impedido de manifestar su propio pensamiento y representa, por tanto, un derecho de cada individuo; pero implica también, por otro lado, un derecho colectivo a recibir cualquier clase de información y a conocer la expresión del pensamiento ajeno.

Además, destacó que dicha dimensión individual de la libertad de expresión “no se agota en el reconocimiento teórico del derecho a hablar o escribir, sino que comprende además, inseparablemente, el derecho a utilizar cualquier medio apropiado para difundir el pensamiento y hacerlo llegar al mayor número de destinatarios". En tal orden de ideas, consideró que "una restricción de las posibilidades de divulgación representa directamente, y en la misma medida, un límite al derecho de expresarse libremente."

A su vez, para la CIDH en su dimensión social la libertad de expresión "es un medio para el intercambio de ideas e informaciones y para la comunicación masiva entre los seres humanos. Así como comprende el derecho de cada uno a tratar de comunicar a los otros sus propios puntos de vista implica también el derecho de todos a conocer opiniones y noticias. Para el ciudadano común tiene tanta importancia el conocimiento de la opinión ajena o de la información de que disponen otros como el derecho a difundir la propia."

Amén de establecer la base conceptual de ese derecho también reparó en el aspecto de los límites; reglas que evidentemente se trasladan al campo del DAIP. En lo concerniente a dicha cuestión estimó que, en virtud de lo previsto en el art. 13.2 de $\mathrm{CADH}$, es la ley la que debe establecer las restricciones a la libertad de información y solamente para lograr fines que la propia Convención señala.

Luego la CIDH señaló que la expresión "necesarias para asegurar", empleada en tal disposición implica que el juicio sobre si una restricción a la libertad de expresión impuesta por un Estado debe ser considera como tal tiene que vincularse con las necesidades legítimas de las sociedades e instituciones democráticas.

Además, precisó que las limitaciones deben estar orientadas a satisfacer un interés público imperativo. Por tal motivo, se consideró que "Entre varias opciones para alcanzar ese objetivo debe escogerse aquélla que restrinja en menor escala el derecho protegido. Dado este estándar, no es suficiente que se demuestre, por 
ejemplo, que la ley cumple un propósito útil u oportuno; para que sean compatibles con la Convención las restricciones deben justificarse según objetivos colectivos que, por su importancia, preponderen claramente sobre la necesidad social del pleno goce del derecho que el artículo 13 garantiza y no limiten más de lo estrictamente necesario el derecho proclamado en el artículo 13. Es decir, la restricción debe ser proporcionada al interés que la justifica y ajustarse estrechamente al logro de ese legítimo objetivo."

A ello debe adicionarse la exigencia prevista en el inciso $2^{\circ}$ del art. 13 cuando señala que "No se puede restringir el derecho de expresión por vías o medios indirectos, tales como el abuso de controles oficiales o particulares de papel para periódicos, de frecuencias radioeléctricas, o de enseres y aparatos usados en la difusión de información o por cualesquiera otros medios encaminados a impedir la comunicación y la circulación de ideas y opiniones."

Según la CIDH dicha cláusula debe leerse juntamente con el art. 1.1 de la Convención mediante la cual los Estados Partes se comprometen a respetar los derechos y libertades reconocidos y a garantizar su libre y pleno ejercicio a toda persona que esté sujeta a su jurisdicción. Por ende, estima que la violación de la $\mathrm{CIDH}$ en este ámbito puede derivarse no sólo de que el Estado imponga por sí mismo restricciones encaminadas a impedir indirectamente la comunicación y la circulación de opiniones e ideas sino también de que no se haya asegurado que la violación no resulte de los controles particulares mencionados en el párrafo 3 del artículo 13.

A partir de lo expuesto la CIDH concluyó las razones de orden público que son válidas para justificar la colegiación obligatoria de otras profesiones no pueden invocarse en el caso del periodismo, habida cuenta que conducen a limitar de modo permanente, en perjuicio de los no colegiados, el derecho de hacer uso pleno de las facultades que reconoce a todo ser humano el aludido art. 13 de la Convención. Por tal razón, resolvió que la normativa por la cual se pretendía imponer la colegiación obligatoria de los periodistas en contraria a la CIDH.

\section{Caso "La Última Tentación de Cristo" 26}

El caso se refiere a la prohibición del Consejo de Calificación Cinematográfica por medio de la cual se rechazó la exhibición de la película "La Última Tentación de Cristo". Es importante poner de resalto que esta decisión fue posteriormente ratificada por la Corte Suprema de Justicia de dicho país.

La CIDH además de reiterar los criterios de la OC 5/85 que hemos expuesto con anterioridad en lo vinculado a la base sustancial, dimensiones y límites de la libertad de

\footnotetext{
${ }^{26}$ Caso "La Última Tentación de Cristo" (Olmedo Bustos y otros) Vs. Chile". Fondo, Reparaciones y Costas. Sentencia de 5 de febrero de 2001. Serie C No. 73.
} 
expresión destacó a dicho derecho "como piedra angular de una sociedad democrática, es una condición esencial para que ésta esté suficientemente informada".

A partir de tal plataforma, el tribunal consideró que existía responsabilidad internacional de Chile por haber dado lugar a actos de censura lo que implica la violación del derecho a la libertad de pensamiento y de expresión consagrado en el artículo 13 de la CADH.

\section{Caso "Ivcher Bronstein Vs. Perú" 27}

El presente caso tuvo lugar a causa de un problema de nacionalidad dado que el actor, de origen israelí, era el propietario mayoritario de un canal de televisión y, posteriormente, adquirió la ciudadanía peruana por naturalización.

La cuestión problemática se suscitó cuando uno de los programas del canal del demandante empezó a transmitir reportajes relacionados con el gobierno del entonces presidente Alberto Fujimori. En ese marco el Poder Ejecutivo del Perú emitió un decreto que reglamentó la ley de nacionalidad y estableció la posibilidad de cancelar la nacionalidad a los peruanos naturalizados. Y en ese contexto se dejó sin efecto legal el título de nacionalidad del señor Ivcher y se le suspendió como accionista mayoritario del canal televisivo. Los recursos presentados en el orden interno de dicho país para cuestionar estas decisiones fueron desestimados.

A partir de ello, en consonancia con lo dictaminado en la OC 5/85, la CIDH remarcó que la dimensión individual del derecho a la libertad de expresión "no se agota en el reconocimiento teórico del derecho a hablar o escribir, sino que comprende además, inseparablemente, el derecho a utilizar cualquier medio apropiado para difundir la información y hacerla llegar al mayor número de destinatarios. En este sentido, la expresión y la difusión del pensamiento y de la información son indivisibles, de modo que una restricción de las posibilidades de divulgación representa directamente, y en la misma medida, un límite al derecho de expresarse libremente".

\section{Caso "Maritza Urrutia Vs. Guatemala"28}

Esta contienda tuvo lugar debido a que la reclamante, quien había desempeñado tareas políticas para la organización revolucionaria del Ejército Guerrillero de los Pobres (EGP), fue secuestrada por miembros de la Inteligencia del Ejército guatemalteco y trasladada a las instalaciones del centro de detención clandestino del Ejército de Guatemala. Allí, fue sometida a largos y continuos interrogatorios y amenazada de

\footnotetext{
${ }^{27}$ Caso "Ivcher Bronstein Vs. Perú". Fondo, Reparaciones y Costas. Sentencia de 6 de febrero de 2001. Serie C No. 74.

${ }^{28}$ Caso "Maritza Urrutia Vs. Guatemala". Fondo, Reparaciones y Costas. Sentencia de 27 de noviembre de 2003. Serie C No. 103.
} 
ser torturada físicamente. Además, fue forzada a prestar una declaración filmada donde se refirió a su participación, la de su ex esposo y la de su hermano en el EGP, justificó su desaparición como una manera de abandonar esa organización e instó a sus compañeros a dejar la lucha armada. Luego, dicho video fue transmitido por dos noticieros de Guatemala.

Posteriormente, fue liberada y se sometió a una amnistía. Ninguna autoridad estatal le preguntó sobre lo que le había sucedido y siguiendo las instrucciones de sus captores brindó una conferencia de prensa en la cual confirmó el contenido del video.

Después de ello, emigró de Guatemala hacia los Estados Unidos, país que le reconoció la condición de refugiada.

La CIDH, en virtud de las probanzas rendidas en la causa consideró que se había violado el derecho a la libertad de Pensamiento y de Expresión debido a que agentes del Estado forzaron a la presunta víctima a expresar públicamente, contra su voluntad, opiniones que no le eran propias e información falsa sobre su secuestro, por medio de actos coercitivos.

\section{Caso “Herrera Ulloa Vs. Costa Rica” 29}

Este precedente se suscitó a raíz de la publicación en un periódico una serie de artículos que vinculaban a un funcionario con diversas conductas ilícitas. Este se sintió afectado y decidió promover una acción civil resarcitoria contra del periodista y del periódico, la que fue acogida por la Corte Suprema de Justicia de Costa Rica emitiendo una sentencia condenatoria en contra de Herrera Ulloa y del periódico como medio informativo en el que se publicaron los artículos difamantes, en carácter de responsable civil solidario. Los recursos interpuestos en el orden interno fueron desestimados.

Aquí la $\mathrm{CIDH}$ reitera los lineamientos establecidos en pronunciamientos anteriores que, como vimos, toman como base la OC 5/85. Es interesante destacar que en dicha sentencia se aborda lo relativo a los alcances de la libertad de expresión en el marco de la actuación de funcionarios públicos, destacando que "es lógico y apropiado que las expresiones concernientes a funcionarios públicos o a otras personas que ejercen funciones de una naturaleza pública deben gozar, en los términos del artículo 13.2 de la Convención, de un margen de apertura a un debate amplio respecto de asuntos de interés público, el cual es esencial para el funcionamiento de un sistema verdaderamente democrático. Esto no significa, de modo alguno, que el honor de los funcionarios públicos o de las personas públicas

\footnotetext{
${ }^{29}$ Caso "Herrera Ulloa Vs. Costa Rica". Excepciones Preliminares, Fondo, Reparaciones y Costas. Sentencia de 2 de julio de 2004. Serie C No. 107.
} 
no deba ser jurídicamente protegido, sino que éste debe serlo de manera acorde con los principios del pluralismo democrático."

\section{Caso "Ricardo Canese Vs. Paraguay" 30}

Los hechos del presente caso se suscitaron durante el debate de la contienda electoral para las elecciones presidenciales del Paraguay de 1993. El demandante, quien era candidato presidencial, declaró en contra de otro candidato por presuntas acciones ilícitas cuando era la máxima autoridad de un consorcio.

En virtud de ello, se presentó una querella criminal en contra de Canese por los delitos de difamación e injuria, proceso en el que fue condenado con la imposición de una pena privativa de la libertad y una multa. Además, fue sometido a una restricción permanente para salir de su país. Posteriormente, la Corte Suprema de Justicia del Paraguay anuló las sentencias condenatorias.

Luego de reiterar los términos de la aludida OC OC 5/85, la CIDH dejó sentado que "en el marco de una campaña electoral, la libertad de pensamiento y de expresión en sus dos dimensiones constituye un bastión fundamental para el debate durante el proceso electoral, debido a que se transforma en una herramienta esencial para la formación de la opinión pública de los electores, fortalece la contienda política entre los distintos candidatos y partidos que participan en los comicios y se transforma en un auténtico instrumento de análisis de las plataformas políticas planteadas por los distintos candidatos, lo cual permite una mayor transparencia y fiscalización de las futuras autoridades y de su gestión".

Asimismo, agregó que "El Tribunal considera indispensable que se proteja y garantice el ejercicio de la libertad de expresión en el debate político que precede a las elecciones de las autoridades estatales que gobernarán un Estado. La formación de la voluntad colectiva mediante el ejercicio del sufragio individual se nutre de las diferentes opciones que presentan los partidos políticos a través de los candidatos que los representan. El debate democrático implica que se permita la circulación libre de ideas e información respecto de los candidatos y sus partidos políticos por parte de los medios de comunicación, de los propios candidatos y de cualquier persona que desee expresar su opinión o brindar información. Es preciso que todos puedan cuestionar e indagar sobre la capacidad e idoneidad de los candidatos, así como disentir y confrontar sus propuestas, ideas y opiniones de manera que los electores puedan formar su criterio para votar. En este sentido, el ejercicio de los derechos políticos y la libertad de pensamiento y de expresión se encuentran íntimamente ligados y se fortalecen entre sí."

\footnotetext{
${ }^{30}$ Caso "Ricardo Canese Vs. Paraguay". Fondo, Reparaciones y Costas. Sentencia de 31 de agosto de 2004. Serie C No. 111.
} 
A partir de tal plataforma la CIDH debió analizar, tomando como base lo dictaminado en la OC 5/85, si para aplicar la responsabilidad ulterior a Canese por sus declaraciones, se cumplió con el requisito de necesidad en una sociedad democrática establecido, como vimos en el art. 13.2 de la CADH. En ese marco y luego de reiterar que "Entre varias opciones para alcanzar ese objetivo, debe escogerse aquélla que restrinja en menor escala el derecho protegido" y que "la restricción debe ser proporcional al interés que la justifica y ajustarse estrechamente al logro de ese legítimo objetivo, interfiriendo en la menor medida posible en el efectivo ejercicio del derecho a la libertad de expresión" agregó lo siguiente: "El control democrático, por parte de la sociedad a través de la opinión pública, fomenta la transparencia de las actividades estatales y promueve la responsabilidad de los funcionarios sobre su gestión pública, razón por la cual debe existir un mayor margen de tolerancia frente a afirmaciones y apreciaciones vertidas en el curso de los debates políticos o sobre cuestiones de interés público".

\section{Caso "Palamara Iribarne Vs. Chile" 31}

Los hechos del presente caso se refieren a la prohibición de la publicación de un libro por un asesor técnico de las Fuerzas Armadas en el cual aborda diversos aspectos relacionados con la inteligencia militar y la necesidad de adecuarla a ciertos parámetros éticos.

A partir de la negativa del señor Palamara Iribarne de detener la publicación de dicho libro, se le inició una causa penal por los delitos de desobediencia e incumplimiento de deberes militares en la que fue condenado a la pena de presidio menor en su grado mínimo, al pago de una multa y a la suspensión del cargo u oficio público durante el tiempo de la condena. Asimismo, con base en la misma base fáctica, se promovió una investigación sumaria administrativa por la comisión de faltas.

La CIDH extendió que, en el presente caso, para que el Estado garantizara efectivamente el ejercicio del derecho a la libertad de pensamiento y de expresión del señor Palamara Iribarne no bastaba con que permitiera que escribiera sus ideas y opiniones sino, que tal protección, comprendía el deber de no restringir su difusión, de forma tal que pudiera distribuir el libro utilizando cualquier medio apropiado para hacer llegar tales ideas y opiniones al mayor número de destinatarios, y que éstos pudieran recibir tal información

Sin embargo dejó en claro que "puede ocurrir que los empleados o funcionarios de una institución tengan el deber de guardar confidencialidad sobre cierta información a la que tienen acceso en ejercicio de sus funciones, cuando el contenido de dicha

\footnotetext{
${ }^{31}$ Caso "Palamara Iribarne Vs. Chile". Fondo, Reparaciones y Costas. Sentencia de 22 de noviembre de 2005. Serie C No. 135.
} 
in formación se encuentre cubierto por el referido deber. El deber de confidencialidad no abarca a la información relativa a la institución o a las funciones que ésta realiza cuando se hubiere hecho pública. Sin embargo, en ciertos casos, el incumplimiento del deber de confidencialidad puede generar responsabilidades administrativas, civiles o disciplinarias."

\section{Caso "Claude Reyes y otros Vs. Chile" 32}

Los hechos del presente conflicto se iniciaron cuando el señor Claude Reyes, Director Ejecutivo de una fundación, solicitó al Comité de Inversiones Extranjeras información relacionada a un proyecto de industrialización forestal y la misma fue denegada. Por tal motivo, se presentó un recurso de protección ante la Corte de Apelaciones de Santiago de Chile el que fue declarado inadmisible.

La cuestión giraba en torno a determinar si la falta de entrega de una parte de la información solicitada a dicho Comité implicó la violación del derecho a la libertad de pensamiento y de expresión, a lo que la CIDH dio una respuesta positiva.

Desde lo conceptual se dejó en claro que el artículo 13 de la Convención, al estipular expresamente los derechos a "buscar" y a "recibir" informaciones, protege el derecho que tiene toda persona a solicitar el acceso a la información bajo el control del Estado ya que "dicho artículo ampara el derecho de las personas a recibir dicha información y la obligación positiva del Estado de suministrarla, de forma tal que la persona pueda tener acceso a conocer esa información".

Además, agregó que la información debe ser entregada a sin necesidad de acreditar un interés directo para su obtención o una afectación personal, salvo en los casos en que se aplique una legítima restricción. Pues se estima que "Su entrega a una persona puede permitir a su vez que ésta circule en la sociedad de manera que pueda conocerla, acceder a ella y valorarla".

También, señaló que "El acceso a la información bajo el control del Estado, que sea de interés público, puede permitir la participación en la gestión pública, a través del control social que se puede ejercer con dicho acceso".

Asimismo, abordó la cuestión de las restricciones en materia de acceso a la información pública destacando que para que las mismas sean válidas deben: a) ser fijadas por ley; b) Tener como fin la protección del interés general; c) Responder a un objetivo permitido por la CADH: que sean necesarias para asegurar "el respeto a los derechos o a la reputación de los demás" o "la protección de la seguridad nacional, el orden público o la salud o la moral públicas" y d) Deben ser necesarias en una sociedad democrática, razonables y adecuadas.

\footnotetext{
${ }^{32}$ Caso "Claude Reyes y otros Vs. Chile. Fondo". Reparaciones y Costas. Sentencia de 19 de septiembre de 2006. Serie C No. 151.
} 
Por último, agregó que "en una sociedad democrática es indispensable que las autoridades estatales se rijan por el principio de máxima divulgación, el cual establece la presunción de que toda información es accesible, sujeto a un sistema restringido de excepciones" y que "Corresponde al Estado demostrar que al establecer restricciones al acceso a la información bajo su control ha cumplido con los anteriores requisitos."

\section{Caso "Albán Cornejo y otros. Vs. Ecuador"33}

Los hechos del presente caso se iniciaron cuando Laura Susana Albán Cornejo ingresó al Hospital Metropolitano en la ciudad de Quito debido a un cuadro clínico de meningitis bacteriana. Unos días después, sufrió un fuerte dolor por lo que el médico residente le prescribió una inyección de diez miligramos de morfina y, al día siguiente, perdió la vida.

En base a ello, sus padres promovieron una acción judicial para determinar la responsabilidad de la muerte de su hija. Uno de los dos médicos investigados por negligencia fue sobreseído mientras que la situación jurídica del otro médico se encontraba pendiente de resolución judicial.

Al resolver la CIDH entendió que el aludido hospital al haber ocultado información valiosa acerca del tratamiento y la muerte de la señorita Albán Cornejo y encubrir la identidad de los médicos responsables de los hechos, violó el art. 13 de la CADH lo que incidió directamente en el derecho de los familiares a conocer la verdad. Por tal razón, consideró que el Estado ecuatoriano debía ser considerado responsable al no proteger el derecho a la información propia que tienen los pacientes y sus familiares afectados y que "Debido a esta omisión se produjo una espera interminable para los fines de la aplicación del derecho y la justicia. Agregaron que la posición tolerante, pasiva y despreocupada del poder público fue la causa por la que los padres de la señorita Albán Cornejo no pudieron acceder a tiempo a la información acerca de su hija, vulnerando el derecho de aquéllos a la información y dejándolos en estado de indefensión".

\section{Caso "Kimel Vs. Argentina"34}

Los hechos del presente caso tuvieron origen en la publicación de un libro titulado "La masacre de San Patricio", escrito por el señor Kimel que se desempeñaba como periodista, escritor e investigador histórico. Este texto analizaba el asesinato de

\footnotetext{
${ }^{33}$ Caso "Albán Cornejo y otros. Vs. Ecuador". Fondo Reparaciones y Costas. Sentencia de 22 de noviembre de 2007. Serie C No. 1.

${ }^{34}$ Caso Caso "Kimel Vs. Argentina." Fondo, Reparaciones y Costas. Sentencia de 2 de mayo de 2008 Serie C No. 177 .
} 
cinco religiosos pertenecientes a la orden palotina, ocurrido en Argentina en 1976, durante la última dictadura militar. Asimismo, en el mismo se criticaba la actuación de las autoridades encargadas de la investigación de los homicidios, entre ellas la de un juez en particular.

El juez mencionado por el señor Kimel en su libro entabló una acción penal en contra de él por el delito de calumnia. Luego de concluido el proceso seguido en su contra se resolvió que aquel debía ser condenado a un año de prisión y al pago de una multa por el delito de calumnia.

Ya hemos visto que la CIDH ha señalado que es la ley - en sentido formal y material - la que debe establecer las restricciones a la libertad de información. Sin embargo, en este caso remarca que "si la restricción o limitación proviene del derecho penal, es preciso observar los estrictos requerimientos característicos de la tipificación penal para satisfacer en este ámbito el principio de legalidad. Así, deben formularse en forma expresa, precisa, taxativa y previa. El marco legal debe brindar seguridad jurídica al ciudadano."

En virtud de ello consideró que Argentina había infringido el derecho a la libertad de expresión consagrado en el artículo 13.1 y 13.2 de la CADH, en relación con la obligación general contemplada en el artículo 1.1 de la misma, en perjuicio del señor Kimel.

\section{Caso "Ríos y otros Vs. Venezuela" 35}

El caso se refiere a la responsabilidad internacional del Estado por las restricciones a la libertad de expresión en perjuicio de veinte trabajadores de un canal de televisión en el marco de sus labores periodísticas, así como la afectación a su integridad personal. En particular, ciertos funcionarios públicos y particulares los amenazaron, hostigaron y agredieron -física y verbalmente-, incluyendo lesiones por disparos de armas de fuego a tales periodistas.

En especial, la CIDH destacó que "Con respecto a las acreditaciones o autorizaciones a los medios de prensa para la participación en eventos oficiales, que implican una posible restricción al ejercicio de la libertad de buscar, recibir y difundir información e ideas de toda índole, debe demostrarse que su aplicación es legal, persigue un objetivo legítimo y es necesaria y proporcional en relación con el objetivo que pretende en una sociedad democrática. Los requisitos de acreditación deben ser concretos, objetivos y razonables, y su aplicación transparente".

Al resolver, consideró que dado que en el caso, los representantes de los demandantes no invocaron que la supuesta falta de acceso a las fuentes oficiales

\footnotetext{
${ }^{35}$ Caso "Ríos y otros Vs. Venezuela". Excepciones Preliminares, Fondo, Reparaciones y Costas. Sentencia de 28 de enero de 2009. Serie C No. 194.
} 
proviniera de una normativa o regulación emanada del Estado concluyendo que "Ios hechos alegados se refieren a su puestas restricciones de facto o impedimentos por vía de hecho, por lo que correspondía a los representantes probar que el Estado restringió el acceso de las presuntas víctimas a determinadas fuentes oficiales de información. Una vez probadas las restricciones por quien las alega, corresponde al Estado sustentar las razones y circunstancias que las motivaron y, en su caso, justificar los criterios en que se basaba para permitir el acceso a los periodistas de algunos medios y no permitirlo a otros."

\section{Caso "Cepeda Vargas Manuel Vs. Colombia" 36}

Los hechos del presente caso tuvieron lugar a partir de la denuncia de la existencia de conductas de violencia sistemática en contra de los miembros del partido político Unión Patriótica (UP). El señor Manuel Cepeda Vargas era comunicador social y líder del Partido Comunista Colombiano (PCC) y de la UP. Fue asesinado cuando se desplazaba desde su vivienda hacia el Congreso de la República debido a su militancia política de oposición y sus publicaciones como comunicador social. A pesar de los diversos recursos que se presentaron en el plano interno, no se realizaron mayores investigaciones ni se sancionaron a todos los responsables.

En este caso la CIDH dijo que "la libertad de expresión, particularmente en asuntos de interés público, garantiza la difusión de información o ideas, incluso las que resultan ingratas para el Estado o cualquier sector de la población. En este sentido, es de resaltar que las voces de oposición resultan imprescindibles para una sociedad democrática, sin las cuales no es posible el logro de acuerdos que atiendan a las diferentes visiones que prevalecen en una sociedad".

\section{Caso "Gelman Vs. Uruguay" 37}

El presente antecedente se verificó cuando a raíz del golpe de Estado acontecido en Uruguay, María Claudia García Iruretagoyena Casinelli, embarazada y de 19 años de edad, fue detenida en 1976 junto con su esposo, Marcelo Ariel Gelman Schubaroff, en su residencia de Buenos Aires por comandos militares uruguayos y argentinos. Ambos fueron llevados a un centro de detención clandestino, donde permanecieron juntos algunos días y posteriormente fueron separados.

Marcelo Gelman fue torturado en dicho centro de detención clandestino y fue ejecutado en 1976. María Claudia García fue trasladada a Montevideo de forma

\footnotetext{
${ }^{36}$ Caso "Cepeda Vargas Manuel Vs. Colombia." Excepciones Preliminares, Fondo, Reparaciones y Costas. Sentencia de 26 de mayo de 2010. Serie C No. 213.

${ }^{37}$ Caso "Gelman Vs. Uruguay". Fondo y Reparaciones. Sentencia de 24 de febrero de 2011 Serie C No. 221. Gelman Vs. Uruguay. Interpretación de la Sentencia 2013.
} 
clandestina por autoridades uruguayas, donde dio a luz a una niña, la que le fue sustraída y dejada en la puerta de la casa de un policía que se quedó con ella. En el año 2000, a la edad de 23 años, María Macarena Tauriño tuvo por primera vez contacto con su abuelo se sometió a una prueba de ADN la que resultó en una identificación positiva.

Los hechos señalados nunca pudieron ser investigados ni sancionados por Uruguay puesto que en 1986 el Parlamento uruguayo aprobó la Ley de Caducidad de la Pretensión Punitiva del Estado mediante la cual se concedió una amnistía en relación con los delitos cometidos en el periodo del régimen militar.

En lo vinculado al tema objeto de estudio, la CIDH dijo que "valora positivamente que exista una ley en Uruguay que proteja el derecho al acceso a la información pública, como lo ha informado el Estado. Si bien en el presente caso no se ha constatado la aplicación de dicha norma a favor de las víctimas, el Tribunal ha observado que una de las limitaciones para avanzar en la investigación es que la información acerca de las graves violaciones de derechos humanos ocurridas durante la dictadura reposa en diferentes archivos de seguridad nacional que se encuentran disgregados y cuyo control no es adecuado. Puesto que tal información puede ser útil para los funcionarios que realizan las investigaciones judiciales al respecto, el Estado deberá adoptar las medidas pertinentes y adecuadas para garantizar el acceso técnico y sistematizado a esa información".

\section{Caso "Contreras y otros Vs. El Salvador" 38}

Los hechos del presente caso se desarrollaron en el marco de un conflicto armado interno en el mencionado país, en donde las fuerzas armadas, en el transcurso de diferentes operativos de contrainsurgencia, sustrajeron y retuvieron a numerosos menores de edad cuyo paradero se desconoce, con excepción de Gregoria Herminia Contreras. A pesar de haberse interpuesto numerosos recursos, no se realizaron mayores diligencias ni se sancionaron a los responsables.

Luego de reiterar los criterios establecidos en decisiones anteriores que hemos analizado, la $\mathrm{CIDH}$ resolvió que en el caso estaba acreditado que la restricción aplicada al acceso a la información no se basó en una ley dado que, en esa época, no existía en Chile legislación que regulara la materia de restricciones al acceso a la información bajo el control del Estado.

Asimismo, agregó que "el Estado no demostró que la restricción respondiera a un objetivo permitido por la Convención Americana, ni que fuera necesaria en una sociedad democrática, ya que la autoridad encargada de responder la solicitud

\footnotetext{
${ }^{38}$ Caso "Contreras y otros Vs. El Salvador". Fondo, Reparaciones y Costas. Sentencia de 31 de agosto de 2011 Serie C No. 232.
} 
de información no adoptó una decisión escrita fundamentada que pudiera permitir conocer cuáles fueron los motivos para restringir el acceso a tal información en el caso concreto. Tal como ha quedado acreditado, la restricción aplicada en el presente caso no cumplió con los parámetros convencionales."

Por último, sostuvo que "el establecimiento de restricciones al derecho de acceso a información bajo el control del Estado a través de la práctica de sus autoridades, sin la observancia de los límites convencionales crea un campo fértil para la actuación discrecional y arbitraria del Estado en la clasificación de la información como secreta, reservada o confidencial, y se genera inseguridad jurídica respecto al ejercicio de dicho derecho y las facultades del Estado para restringirlo."

\section{Caso “Fontevecchia y D'Amico Vs. Argentina" 39}

El caso tuvo lugar en razón de dos publicaciones consignadas en una revista de la que los actores eran periodistas editores, donde se vinculaba al entonces Presidente de Argentina, Carlos Menem, con la existencia de un presunto hijo no reconocido por él.

El señor Menem demandó civilmente a la editorial de la revista así como a sus editores a los efectos de obtener un resarcimiento económico por el alegado daño moral causado por la supuesta violación del derecho a la intimidad, consecuencia de las publicaciones de la revista. Además, se solicitó la publicación íntegra de la sentencia a cargo de los demandados.

En el año 2001 la Corte Suprema confirmó la sentencia recurrida que hizo lugar a la demanda y condenó a la editorial y a Jorge Fontevecchia y Héctor D'Amico a abonar una suma en concepto de indemnización.

La CIDH consideró que se había violado la libertad de expresión de los demandantes apuntando que "Dada la importancia de la libertad de expresión en una sociedad democrática y la elevada responsabilidad que ello entraña para quienes ejercen profesionalmente labores de comunicación social, el Estado no sólo debe minimizar las restricciones a la circulación de la información sino también equilibrar, en la mayor medida de lo posible, la participación de las distintas informaciones en el debate público, impulsando el pluralismo informativo. En consecuencia, la equidad debe regir el flujo informativo. En estos términos puede explicarse la protección de los derechos humanos de quien enfrenta el poder de los medios y el intento por asegurar condiciones estructurales que permitan la expresión equitativa de las ideas."

\footnotetext{
${ }^{39}$ Caso "Fontevecchia y D'Amico Vs. Argentina." Fondo, Reparaciones y Costas. Sentencia de 29 de noviembre de 2011. Serie C No. 238.
} 


\section{Caso "Mémoli Vs. Argentina" 40}

El caso alude a la violación al derecho a la libertad de expresión de Carlos y Pablo Carlos Mémoli, por la condena penal impuesta a las víctimas debido a sus denuncias públicas de la venta supuestamente irregular de nichos del cementerio local, por parte de la Comisión Directiva de una asociación mutual de la ciudad de San Andrés de Giles.

Asimismo, los demandantes fueron sometidos a un proceso civil mediante el cual se pretendía hacer valer una indemnización establecida en el proceso penal. En dicho proceso, se dispuso el embargo de sus bienes lo que, en la práctica, ha tenido un efecto sancionatorio e inhibitorio de la libertad de expresión, con consecuencias en el proyecto de vida de los señores Mémoli.

En este marco la CIDH sostuvo que "existe un deber del periodista de constatar en forma razonable, aunque no necesariamente exhaustiva, los hechos en que fundamenta sus opiniones. Es decir, resulta válido reclamar equidad y diligencia en la confrontación de las fuentes y la búsqueda de información. Esto implica el derecho de las personas a no recibir una versión manipulada de los hechos. En consecuencia, los periodistas tienen el deber de tomar alguna distancia crítica respecto a sus fuentes y contrastarlas con otros datos relevantes".

A partir de tal cuestión, sostuvo que "el establecimiento de responsabilidades ulteriores a los señores Mémoli por el ejercicio de su libertad de expresión estaba previsto en la ley, obedecía un objetivo permitido por la Convención y no resulta manifiestamente desmedido o desproporcional, dada las circunstancias del presente caso y el análisis realizado por las autoridades judiciales internas. Por tanto, la Corte considera que Argentina no violó el artículo 13 de la Convención Americana, en relación con los artículos 1.1 y 2 de la misma, en perjuicio de Carlos y Pablo Mémoli.

\section{La jurisprudencia de la Corte Suprema}

Como se sabe, la jurisprudencia de la Corte Suprema de Justicia de la Nación es abundante con relación a derecho a la Libertad de pensamiento y expresión ${ }^{41}$. Esta circunstancia adquiere singular importancia si tenemos en cuenta que, según hemos visto, en el marco interamericano el derecho de acceso a la información pública opera como un desprendimiento de aquel.

La referida vinculación, incluso, ha sido admitida explícitamente por el Alto Tribunal al señalar que la libertad de prensa que ésta confiere al derecho de dar y

\footnotetext{
${ }^{40}$ Caso "Mémoli Vs. Argentina". Excepciones Preliminares, Fondo, Reparaciones y Costas. Sentencia de 22 de agosto de 2013. Serie C No. 265.

${ }^{41}$ Fallos 315:1492 “Ekmekdjian c Sofovich" (1992) Fallos, 331:1530 “Patitó, José Ángel y otro c/Diario La Nación y otros" (2008) Fallos, 321:885 "Petric" (1998) entre muchos otros.
} 
recibir información una especial relevancia que se hace aún más evidente para con la difusión de asuntos atinentes a la cosa pública. ${ }^{42}$ Pues para la Corte federal "la expresión y la difusión del pensamiento y de la información son indivisibles, de modo que una restricción a las posibilidades de divulgación representa directamente, y en la misma medida, un límite al derecho de expresarse libremente". ${ }^{43}$

Específicamente, en el derecho a la información fue reconocido expresamente en la causa "Urteaga" ${ }^{44}$ al acoger la pretensión que tenía por objeto conocer si en determinado organismos obraban constancias del fallecimiento del desaparecido hermano del actor y, en su caso, la localización de sus restos.

Asimismo, en otro precedente en donde se discutían los alcances del derecho de acceder a la información que sobre la persona del actor obraba en el servicio de inteligencia del Estado, señaló que los jueces cuentan con la potestad de verificar, a instancias del interesado, si las razones dadas por la secretaría de inteligencia justifican en el caso la negativa a suministrar la información, para lo cual se encuentran habilitados para tomar conocimiento personal y directo de los datos solicitados asegurando el mantenimiento de su confidencialidad. ${ }^{45}$

También, ha resuelto que un medio periodístico no puede invocar válidamente que sea del interés público conocer el estado físico del cuerpo de una persona fallecida, máxime cuando se trata de un aspecto que pertenece claramente al ámbito de la intimidad personal y familiar, que se difunde sin razón superior que lo justifique y se deja expuesto a la vista de los extraños destruyendo tal condición de lo íntimo, es decir, de aquello que sólo algunos tienen derecho a conocer. ${ }^{46}$

A su vez, en otro caso consideró que la de acuerdo con la garantía consagrada por el art. 43, tercer párrafo de la CN y en el inc. 1 del art. 13 de la CADH los causahabientes de las personas fallecidas por el obrar de grupos subversivos pueden ejercer su derecho a la información objetiva, ante las autoridades administrativas y judiciales que correspondan, incluida la Subsecretaría de Derechos Humanos. ${ }^{47}$

Más cerca en el tiempo, al resolver la causa "Asociación de Derecho Civiles" 48 en el año 2012 la Corte Suprema de Justicia de la Nación dictó su primera sentencia en donde reconoce sin corta pisas y de manera amplia el derecho de acceso a la

42 Fallos, 316:1623, "Pérez Arriaga, Antonio c/ Arte Gráfica Editorial Argentina S.A. (1993).

43 Fallos, 330:3908, “Editorial Rio Negro SA c/ Neuquén, Provincia del” (2008).

${ }^{44}$ Fallos, 321:2767, “Urteaga, Facundo Raúl c/ Estado Nacional - Estado Mayor Conjunto de las FF.AA.- s/ amparo ley 16.986" (1998).

45 Corte Suprema de Justicia de la Nación, 19/04/2011, “R. P., R. D. c. Estado Nacional - Secretaría de Inteligencia del Estado", LA LEY 18/05/2011, 11, Supl. Adm. 2011 (junio).

${ }^{46}$ Corte Suprema de Justicia de la Nación, 30/10/2007, "Franco, Julio César c. Diario La Mañana y/u otros", LA LEY 14/12/2007, p. 6.

47 Corte Suprema de Justicia de la Nación, 19/04/2011, “Oharriz, Martín J. c. Ministerio de Justicia y Derechos Humanos", La Ley Online AR/JUR/6587/2003.

48 C.S.J.N., 04/12/2012, "Asociación Derechos Civiles el EN — PAMI — (dto.1172/03) s/ amparo ley 16.986", A. 917. XLVI. 
información pública poniendo sobre el tapete muchos asuntos que hasta el momento eran motivo de discusiones doctrinarias y sentencias de tribunales inferiores.

Se trataba de la acción de amparo promovida por la Asociación por los Derechos Civiles (ADC) en contra del Instituto Nacional de Servicios Sociales para Jubilados y Pensionados (PAMI) con el objeto de que se hiciera entrega de la información relativa a cómo dicha entidad repartía la pauta oficial.

El eje central de la contienda rondaba en torno a las posibilidades de aplicación del Decreto 1172/03 a la demandada en tanto su carácter de persona pública no estatal. Es decir, se procuraba dilucidar si la accionada podía ser considerada como legitimado pasivo del derecho de acceso a la información pública.

El Alto Tribunal entendió que al tratarse de un derecho constitucional netamente operativo debe permitirse el acceso a la información con independencia de que existan normas al respecto. Por tales motivos, consideró que aquel decreto se aplica a todas las autoridades públicas de manera supletoria en la medida en que carezca de regulación.

Para concluir de tal modo sostuvo que "aun cuando el recurrente no posea naturaleza estatal, dadas sus especiales características y los importantes y trascendentes intereses públicos involucrados, la negativa a brindar la información requerida constituye un acto arbitrario e ilegítimo en el marco de los principios de una sociedad democrática e implica, en consecuencia, una acción que recorta en forma severa derechos que son reservados - como se verá- a cualquier ciudadano, en tanto se trate de datos de indudable interés público y que hagan a la transparencia y a la publicidad de gestión de gobierno, pilares fundamentales de una sociedad que se precie de ser democrática."

Asimismo, haciendo hincapié en el tema de la legitimación pasiva resolvió que para que los Estados cumplan con su obligación de adecuar su ordenamiento interno a los tratados de derecho humanos "no solo deben garantizar este derecho en el ámbito puramente administrativo o de instituciones ligadas al Poder Ejecutivo, sino a todos los órganos del poder público" para concluir que "Dicha amplitud supone incluir como sujetos obligados no solamente a los órganos públicos estatales, en todas sus ramas y niveles, locales o nacionales, sino también a empresas del Estado, hospitales, las instituciones privadas o de otra índole que actúan con capacidad estatal o ejercen funciones públicas" teniendo como norte el principio de máxima divulgación.

Recientemente, tuvo ocasión, nuevamente, de analizar los alcances del DAIP al resolver la causa "CIPPEC". ${ }^{49}$ Se trataba de un caso suscitado a partir del pedido formulado por la actora a los fines de que la administración pública le permitiera

\footnotetext{
${ }^{49}$ CSJN, 26/03/2014, “CIPPEC c/ EN — Mo Desarrollo Social — dto. 1172/03 s/ amparo ley 16.986”, causa C.830.XLVI.
} 
conocer la información relativa a los datos de las transferencias en gastos corrientes realizadas por el Estado Nacional al sector privado en los conceptos "Ayuda social a las personas" y "Transferencias a Otras Instituciones Culturales y Sociales sin Fines de Lucro" otorgadas durante 2006 y 2007, se denegó dicha solicitud argumentando que se encontraba exceptuada de brindarla por tratarse de información sensible.

A tales efectos, invocó el art. 16 inc. 1ํinciso i) del Anexo VII del Decreto $1172 / 03^{50}$ que prescribe que los sujetos obligados quedan exceptuados de otorgar la información cuando involucre datos personales de carácter sensible "cuya publicidad constituya una vulneración del derecho a la intimidad y al honor, salvo que se cuente con el consentimiento expreso de la persona a que refiere la información solicitada".

A los fines de contextualizar correctamente la contienda cabe recordar que el art. 11 , ap. 1 de la ley $25.326^{51}$ al regular el sistema de Protección de los Datos Personales dispone que "Los datos personales objeto de tratamiento solo pueden ser cedidos para el cumplimiento de los fines directamente relacionados con el interés legítimo del cedente y del cesionario y con el previo consentimiento del titular de los datos, al que se le debe informar sobre la finalidad de la cesión e identificar al cesionario o los elementos que permitan hacerlo".

Ese rechazo motivó la promoción de una acción de amparo que denegada en primera instancia fue acogida por el tribunal de Alzada. Tal circunstancia obligó al Estado Nacional a interponer un recurso extraordinario federal a los fines de que la Corte resolviera si la limitación invocada por la administración pública resultaba ajustada a derecho.

Al dictar sentencia, el Máximo tribunal, confirmó la resolución objeto de cuestionamiento, dejando en claro a partir del contenido de los instrumentos internacionales y en base a lo prescripto en el art. 6 anexo VII del decreto 1172/03, que el derecho de acceso a la información pública parte de una legitimación activa amplia o universal, ${ }^{52}$ lo que impide exigir un interés calificado o especial a quien solicita la información, continuando la línea abierta en la causa "ADC". ${ }^{53}$

Partiendo de esa base, la Corte consideró que el art. 11 de la ley 25.326 cuando subordina la cesión de esos datos a la existencia de un interés legítimo,

\footnotetext{
50 B.0. 4/12/2003.

51 B.0. 2/11/2000.

52 A tales efectos recordó que "se trata de información de carácter público, que no pertenece al Estado sino que es del pueblo de la Nación Argentina y, en consecuencia, la sola condición de integrante de la comunidad resulta suficiente para justificar la solicitud. De poco serviría el establecimiento de políticas de transparencia y garantías en materia de información pública si luego se dificulta el acceso a ella mediante la implementación de trabas de índole meramente formal. Ello es así ya que el acceso a la información tiene como propósito coadyuvar a que los integrantes de la sociedad ejerzan eficazmente el derecho a saber, por lo que el otorgamiento de la información no puede depender de la acreditación de un interés legítimo en ésta ni de la exposición de los motivos por los que se la requiere."

${ }^{53}$ C.S.J.N., 04/12/2012, “Asociación Derechos Civiles el EN — PAMI — (dto.1172/03) s/ amparo ley 16.986", A. 917. XLVI.
} 
no comprende aquellos supuestos concernientes a información personal que forma parte de la gestión pública. Pues, según su opinión "la restricción contemplada en el precepto debe entenderse como un límite a la circulación de datos personales entre personas públicas o privadas que se dedican a su tratamiento, mas no parece posible extender sin más sus previsiones a supuestos de interés público como el planteado en autos, pues ello significaría desconocer, o cuanto menos obstaculizar, el pleno goce de un derecho humano reconocido tanto en nuestra Constitución Nacional como en los Tratados Internacionales que la República Argentina ha suscripto."

Si bien dicha conclusión bastaba desestimar el remedio federal intentado por el Estado, a mayor abundamiento, la Corte analiza, asimismo, la defensa propuesta desde la perspectiva de la razonabilidad.

A través ese enfoque también arribó al mismo resultado al remarcar que "resulta indiscutible que para asegurar la publicidad de los actos de gobierno que caracteriza a un sistema republicano y garantizar el correlativo derecho a la información que asiste a la actora, no resulta suficiente con dar a conocer las normas que establecieron estos programas sociales, las partidas de presupuesto ejecutadas en ese marco o información estadísticamente cuantitativa relativa al número total de los beneficiarios. Por el contrario, la publicidad debe atravesar todas las etapas del accionar público y decantar desde la norma general a todo lo que hace a su instrumentación particular ya que solo así es posible prevenir en forma efectiva la configuración de nichos de impunidad."

Por tal motivo, estimó que la petición de información efectuada por la actora tenía por objeto conocer información pública y que a través de dicho instrumentos se permitía realizar "un exhaustivo control social sobre el modo en que los funcionarios competentes han asignado estos subsidios resulta necesario acceder al listado de los distintos beneficiarios y receptores de los planes sociales."

En virtud de ello, el cimero Tribunal concluyó que la negativa del Estado a brindar esta información al recurrente resultaba ilegal e irrazonable en tanto "el listado cuya divulgación se persigue no se refiera al origen racial y étnico de los involucrados, sus opiniones políticas, convicciones religiosas, filosóficas o morales, su afiliación sindical o se trate de información referente a la salud o a la vida sexual, no se conculca el derecho a su intimidad ni se afecta su honor."

\section{VIIII Objeto de acceso}

En primer lugar, debe señalarse que este derecho no implicaúnicamente el acceso a la documentación administrativa, típico derecho que se consigue con la vista del expediente y que requiere la acreditación de una situación jurídico subjetiva activa, ${ }^{54}$

\footnotetext{
${ }^{54} \mathrm{Vg}$. Derecho subjetivo o interés legítimo.
} 
sino que lo que procura es obtener cierta información que se encuentra en manos estatales o privadas pero vinculadas a la administración, tal como veremos luego a estudiar el tema de la legitimación pasiva.

El universo de la información pública se encuentra compuesto por toda aquella que pueda ser comunicable; 55 es decir comprende todos los expedientes, archivos, registros, bases de datos y documentos escritos, fotografías, grabaciones, etc., que se encuentren en poder de autoridades públicas o privadas que realizan un cometido público o que reciben un subsidio estatal. ${ }^{56}$

El acceso a la información pública implica, entonces, la posibilidad de conocer los documentos administrativos, la normativa administrativa y los procedimientos que se tramiten ante las autoridades públicas y la que se halla en manos privadas, con las salvedades a que haremos referencia más adelante.

En el art. 8 de la Ley $25152^{57}$ se señala que documentación de carácter físico y financiero producida en el ámbito de la Administración Nacional y que se detalla a continuación, tiene el carácter de información pública y será de libre acceso para cualquier institución o persona interesada en conocerla: a) Estados de ejecución de los presupuestos de gastos y del cálculo de recursos, hasta el último nivel de desagregación en que se procesen; b) Ordenes de compra, todo tipo de contratos firmados por autoridad competente, así como las rendiciones de fondos anticipados; c) Ordenes de pago ingresadas a la Tesorería Nacional y al resto de las tesorerías de la Administración Nacional; d) Pagos realizados por la Tesorería Nacional y por el resto de las tesorerías de la Administración Nacional; e) Datos financieros y de ocupación del Sistema Integrado de Recursos Humanos que administra la Secretaría de Hacienda, sobre personal permanente, contratado y transitorio, incluido el de los proyectos financiados por organismos multilaterales; f) Listado de beneficiarios de jubilaciones, pensiones y retiros de las Fuerzas Armadas y de Seguridad; g) Estado de situación, perfil de vencimientos y costo de la deuda pública, así como de los avales y garantías emitidas, y de los compromisos de ejercicios futuros contraídos; h) Listados de cuentas a cobrar; i) Inventarios de bienes inmuebles y de inversiones financieras; j) Estado del cumplimiento de las obligaciones tributarias, previsionales y aduaneras de las sociedades y las personas físicas ante la Administración Federal de Ingresos Públicos conforme a la reglamentación que ella misma determine; k) Información acerca de la regulación y control de los servicios públicos, obrante en los entes reguladores y de control de los mismos; I) Toda la información necesaria para que pueda realizarse el control comunitario de los gastos sociales a los que se

\footnotetext{
${ }_{55}$ Cfr. CARRANZA TORRES, Luis y PALAZZI, Pablo I., "Derecho de acceso a la información pública y derecho de acceso a la información privada (habeas data): semejanzas y diferencias", JA. 2003-IV, p. 68.

${ }^{56}$ Cfr. BASTERRA, M., op. cit, p. 411/412.

${ }^{57}$ B.O. 21/09/1999.
} 
refiere el artículo 5ㅜㅗ inciso b), de la presente ley. La información precedente será puesta a disposición de los interesados por el señor Jefe de Gabinete de Ministros; m) Toda otra información relevante necesaria para que pueda ser controlado el cumplimiento de las normas del sistema nacional de administración financiera y las establecidas por la presente ley.

\section{Principios aplicables}

La esencia adjetiva del pedido de acceso a la información pública hace aplicables algunos principios propios del procedimiento administrativo general y que resultan insoslayables para el correcto desenvolvimiento de este cauce específico de participación ciudadana. ${ }^{58}$ Entre los de carácter específico se destacan los siguientes:

1. Congruencia: La información que brinda la persona pública o privada —que se encuentre obligada normativamente en tal sentido- debe ser conteste con la solicitada por el requirente, pues si se otorgan datos generales o abstractos se estará vedando solapadamente el DAIP.

2. Completitud: Además de ser congruente, la información que se brinda debe ser completa y no parcializada, salvo que se encuentre limitada por norma expresa, tal como lo ordena el art. 4 del Decreto 1172/03.

Asimismo, el art. 17 de dicho cuerpo normativo prevé que en el caso que existiere un documento que contenga información parcialmente reservada, los sujetos enumerados en el art. 2 deben permitir el acceso a la parte de aquella que no se encuentre contenida entre las excepciones detalladas en el artículo 16.

Sin embargo, debe tenerse presente que si la información pública está parcialmente limitada y el otorgamiento de la que se puede brindar induce a confusión, no se entiende o pierde sentido puede ser limitada en su totalidad por la autoridad estatal.

También debe tenerse presente que en caso de ser posible, puede confeccionarse una versión del documento que tache o cubra solamente las partes del documento sujetas a la excepción.

3. Adecuación: Asimismo, debe aportarse toda aquella información pública que guarde directa vinculación con el objeto de petición, habida cuenta que una actitud contraria del sujeto pasivo obligado puede derivar en el cercenamiento del derecho de acceso. ${ }^{59}$

4. Gratuidad: A los fines de acceder a la información no puede exigirse al requirente el pago de tasas, aranceles o contribuciones, ni tampoco contar con

\footnotetext{
58 Para ampliar puede verse: BUTELER, Alfonso y CORVALAN, Juan G, “Los principios del procedimiento informativo", El Derecho, Suplemento de Derecho Administrativo, 18/12/2008, p. 1/4.

59 Cfr. Art. 4을 Decreto 1172/03.
} 
patrocinio letrado obligatorio. En tal sentido, el art. 9 de Decreto 1172/03 prescribe que el acceso público a la información es gratuito en tanto no se requiera su reproducción pero si pretende sacar copias éstas son a costa del solicitante.

Con tal orientación la Ley Modelo Interamericana sobre acceso a la información ${ }^{60}$ establece en su art. 28 que "El solicitante sólo pagará el costo de reproducción de la información solicitada y, de ser el caso, el costo de envío, si así lo hubiese requerido. La información enviada de manera electrónica no podrá tener ningún costo" y que "EI costo de reproducción no podrá exceder el valor del material en el que se reprodujo la información solicitada; el costo del envío no deberá exceder el costo que éste pudiera tener en el mercado. El costo del mercado, para este propósito, deberá ser establecido periódicamente por la Comisión de Información."

5. Oportunidad: La información debe ser otorgada en un plazo razonable que deberá determinarse en cada supuesto por la reglamentación vigente, pues de lo contrario la demora puede implicar el aniquilamiento del derecho. ${ }^{61}$ En caso de no preverse un plazo consideramos que debe aplicarse el plazo de 10 días, tal como lo establece el art. 1 inc. e) apart. 4 de la ley 19.549 para el procedimiento administrativo general en la órbita federal.

6. Veracidad: La información que se brinda debe ser verdadera y auténtica, ${ }^{62}$ siendo responsable de ello el funcionario que se encuentra obligado a brindarla. Cabe destacar que este principio goza de jerarquía constitucional en lo relativo los servicios públicos de conformidad a lo establecido en el art. 42 C.N. sean estos prestados por el propio Estado o por concesionarios o licenciatarios.

7. Igualdad: El principio de la igualdad, como se sabe, tiene raigambre constitucional por su recepción expresa en el art. 16 de la Ley Fundamental. La proyección del mismo sobre el procedimiento administrativo de acceso a la información pública se traduce en no denegar la información que ha sido dada a otro requirente. Tampoco, puede retacearse la información basada en criterios a priori discriminatorios como aquellos basadas en el origen nacional, máxime teniendo en cuenta el carácter universal de este derecho, salvo que esa limitación aparezca como razonable en el caso concreto. Con relación a ello, la Corte Nacional ha señalado que cuando se impugna una categoría infraconstitucional basada en el origen nacional "corresponde considerarla sospechosa de discriminación y portadora de una presunción de inconstitucionalidad que corresponde a la demandada levantar". ${ }^{63}$

\footnotetext{
60 Consejo Permanente de la OEA (abril 2010) (Documento presentado por el Grupo de Expertos sobre Acceso a la Información coordinado por el Departamento de Derecho Internacional, de la Secretaría de Asuntos Jurídicos, de conformidad con la resolución AG/RES. 2514 (XXXIX-O/09) de la Asamblea General.

${ }^{61} \mathrm{Si}$ la información se solicita, por ejemplo, para impugnar un acto administrativo dictado en el marco de un procedimiento licitatorio y la misma se brinda una vez vencidos los plazos para interponer los recursos la información será inútil. Cfr. Art. 4ํ Decreto 1172/03.

62 Cfr. Art. 4을 Decreto 1172/03.

63 Fallos: 327:5118 "Hooft".
} 
Tal como lo ha destacado, Gelli existen elementos tales como la raza, el sexo, la nacionalidad, la edad, que poseen una fuerte presunción de discriminación arbitraria. Esta autora señala que en estos casos debe haber un control de fuerte de razonabilidad en razón de que existe una cierta presunción de inconstitucionalidad ${ }^{64}$ Este derecho se encuentra garantizado por el art 7으 del Decreto 1172/03.

8. Universalidad: Debe brindarse la información a cualquier persona que la solicite sin limitación. Por tal motivo, resulta aconsejable que el derecho a acceder a la información pública debe ser extendido a todos los ciudadanos, ${ }^{65}$ por tratarse de un derecho de titularidad universal, ${ }^{66}$ criterio que ha sido seguido por los ordenamientos de Estados Unidos, Francia, Canadá, Brasil y Colombia ${ }^{67}$ sin poder exigirse ni siquiera, la justificación de las razón que lleva al interesado a pedirla.

Esta solución, afortunadamente ha sido plasmada en el Decreto 1172/03 en su art. 6으 al establecer que “Toda persona física o jurídica, pública o privada, tiene derecho a solicitar, acceder y recibir información, no siendo necesario acreditar derecho subjetivo, interés legítimo ni contar con patrocinio letrado".

Tal circunstancia y la amplitud con que ha sido formulado este derecho, permite sostener que los extranjeros también tienen el derecho para requerir la información pública, de conformidad a lo dispuesto por el art. 20 C.N. en cuanto establece que gozan de los mismos derechos que los ciudadanos argentinos. ${ }^{68}$

9. Accesibilidad: El conocimiento de la información por parte del ciudadano debe ser inmediata y sin retaceos. En tal orden de ideas, el art. 10 del art. 10 del Decreto 1172/03 dispone que los sujetos en cuyo poder obre la información deben prever su adecuada organización, sistematización y disponibilidad, asegurando un amplio y fácil acceso. La información debe ser provista sin otras condiciones más que las expresamente establecidas en el presente. Asimismo deben generar, actualizar y dar a conocer información básica, con el suficiente detalle para su individualización, a fin de orientar al público en el ejercicio de su derecho.

10. Flexibilidad: Debe facilitarse al máximo el acceso a la información. Ello exige que las normas establezcan un modo lo más sencillo posible de ejercicio del derecho y que los funcionarios o empleados públicos realicen buenas prácticas administrativas, evitando que la excesiva burocracia termine frustrando la esencial del derecho e implementado para ello el uso de las nuevas tecnologías.

\footnotetext{
${ }^{64}$ GELLI, María Angélica, Constitución de la Nación Argentina, op. cit., p. 257.

${ }^{65}$ MENDEZ, Luis M., y PALAZZI, Pablo A., "Un caso de derecho de acceso a la información pública", E.D., 180:426.

${ }^{66}$ Cfr. GAMERO CASADO, Eduardo y FERNÁNDEZ RAMOS, Severiano, Manual básico de derecho administrativo, Madrid, Tecnos, 2007, 4aㅡ. Ed. p. 265.

67 Cfr. DIAZ CAFFERATA, Santiago, “El derecho de acceso a la información pública: situación actual, y propuestas para una ley", Tesina presentada para acceder al título de Magíster en la Universidad Austral, 2007, Inédita.

${ }^{68}$ Cfr. ZARINI, Helio J., Derecho constitucional, Buenos Aires, Astrea, 1999, 2ª Ed. act. y ampl., p. 545/6.
} 
11. Máxima divulgación: En una sociedad democrática es indispensable que las autoridades públicas se rijan por el principio de máxima divulgación según el cual se presume de que toda información es accesible, sujeto a un sistema restringido de excepciones y obliga a tener una conducta activa en la difusión de la información. Este principio, como vimos, ha sido receptado por la jurisprudencia de la Corte Suprema ${ }^{69}$ y de la Corte Interamericana de Derechos Humanos. ${ }^{70}$

En igual medida, la Ley Modelo Interamericana sobre acceso a la información señala en el art. 2 que se basa en el principio de máxima publicidad "de tal manera que cualquier información en manos de instituciones públicas sea completa, oportuna y accesible, sujeta a un claro y preciso régimen de excepciones, las que deberán estar definidas por ley y ser además legitimas y estrictamente necesarias en una sociedad democrática."

12. In dubio pro acceso: Como hemos visto, la información pública se presume accesible y las restricciones al derecho de acceso son de interpretación restrictiva y deben ser establecidas por el poder legislativo. Por consiguiente en caso de duda debe permitirse el conocimiento de la misma.

Con tal orientación, la Ley Modelo Interamericana sobre acceso a la información establece en el art. 8 que "Toda persona encargada de la interpretación de esta Ley, o de cualquier otra legislación o instrumento normativo que pueda afectar al derecho a la información, deberá adoptar la interpretación razonable que garantice la mayor efectividad del derecho a la información."

\section{Titularidad del derecho informativo}

Resulta aconsejable que el derecho a acceder a la información pública sea extendido a todos los ciudadanos, por tratarse de un derecho humano fundamental de titularidad universal, criterio que como vimos ha sido seguido por muchos ordenamientos del derecho comparado sin poder exigirse ni siquiera la justificación de las razones que llevan al interesado a pedirla.

Esta solución, afortunadamente ha sido plasmada en el Decreto 1172/03 en su art. 6o al establecer que "Toda persona física o jurídica, pública o privada, tiene derecho a solicitar, acceder y recibir información, no siendo necesario acreditar derecho subjetivo, interés legítimo ni contar con patrocinio letrado".

\footnotetext{
${ }^{69}$ CSJN, 26/03/2014, “CIPPEC c/ EN — № Desarrollo Social — dto. 1172/03 s/ amparo ley 16.986”, causa C.830.XLVI.

${ }^{70} \mathrm{CIDH}$, "Claude Reyes y otros Vs. Chile". Fondo, Reparaciones y Costas. Sentencia de 19 de septiembre de 2006. Serie C No. 151.
} 


\section{Legitimación}

Ahora bien, del hecho de que una persona sea titular del derecho informativo no puede derivarse sin más, la circunstancia de que posea siempre y en todos los casos legitimación activa para requerirla ya que ello dependerá de la naturaleza de la información que se solicita y de los derechos que pueda comprometer la misma. Pues, por ejemplo, no podrá solicitarse el acceso a un expediente administrativo en donde se está tramitando un sumario administrativo a un tercero pues se estaría afectado su derecho a la intimidad. Ello revela que si bien la legitimación es amplia habrá que adecuar esa regla a cada caso particular.

\section{Activa}

La cuestión relativa a la legitimación activa en materia de información pública implica un cambio en la concepción tradicional del derecho administrativo nacional y local que solo tutelaba la situación jurídica subjetiva de aquellas personas que era titulares de un derecho subjetivo, un interés legítimo o un derecho colectivo, relevando a la figura del interés simple a una simple denuncia a la administración.

En materia de acceso a la información pública, en cambio, cualquier persona - aun la que es titular de un interés simple- se encuentra habilitada para requerirla y, en caso de que sea denegada o brindada parcialmente, puede utilizar todos los mecanismos administrativos y judiciales previstos al efecto en el ordenamiento jurídico federal.

Con relación a ello ha dicho la Corte Suprema que "En efecto, se trata de información de carácter público, que no pertenece al Estado sino que es del pueblo de la Nación Argentina y, en consecuencia, la sola condición de integrante de la comunidad resulta suficiente para justificar la solicitud. De poco serviría el establecimiento de políticas de transparencia y garantías en materia de información pública si luego se dificulta el acceso a ella mediante la implementación de trabas de índole meramente formal. Ello es así ya que el acceso a la información tiene como propósito coadyuvar a que los integrantes de la sociedad ejerzan eficazmente el derecho a saber, por lo que el otorgamiento de la información no puede depender de la acreditación de un interés legítimo en ésta ni de la exposición de los motivos por los que se la requiere". ${ }^{71}$

Desde lo jurisprudencial se ha reconocido en más de un precedente la legitimación activa a legisladores nacionales para solicitar información en los términos del decreto 1172/2003. ${ }^{72}$

\footnotetext{
${ }^{71}$ CSJN, 26/03/2014, “CIPPEC c/ EN — Mo Desarrollo Social — dto. 1172/03 s/ amparo ley 16.986”, causa C.830.XLVI.

72 Cámara Nacional de Apelaciones en lo Contencioso administrativo Federal, sala V, 18/10/2007, "Morales, Gerardo Rubén y otro c. Estado Nacional — Ministerio de Economía”, LA LEY 2008-E , 272; Idem, 19/06/2013, “Gil Lavedra, Ricardo Rodolfo c. EN-M de Justicia y DDHH”, LA LEY 2013-E, 156.
} 


\section{Pasiva}

En lo hace a la legitimación pasiva, entre los sujetos obligados a proporcionar la información se encuentran todas las administraciones públicas centralizadas, descentralizadas, entidades autárquicas, autoridades de control, empresas y sociedades estatales, universidades nacionales, personas públicas no estatales en lo que hace al cometido público delegado, e incluso empresas privadas que tengan a su cargo cometidos públicos como los concesionarios de servicios públicos.

A esta nómina, el Decreto 1172/03 agrega las organizaciones privadas a las que se hayan otorgado subsidios o aportes provenientes del sector público nacional, así como a las instituciones o fondos cuya administración, guarda o conservación esté a cargo del Estado Nacional a través de sus jurisdicciones o entidades y a las empresas privadas a quienes se les hayan otorgado mediante permiso, licencia, concesión o cualquier otra forma contractual, la prestación de un servicio público o la explotación de un bien del dominio público

El art. 3 de la Ley Modelo Interamericana sobre acceso a la información dice que la ley "se aplica a toda autoridad pública perteneciente a todas las ramas del gobierno (Poderes Ejecutivo, Legislativo y Judicial) y en todos los niveles de la estructura gubernamental interna (central o federal, regional, provincial o municipal); se aplica también a los órganos, organismos o entidades independientes o autónomos de propiedad del gobierno o controlados por el mismo, bien actuando por facultades otorgadas por la Constitución o por otras leyes y se aplica asimismo a las organizaciones privadas que reciben fondos o beneficios públicos sustanciales (directa o indirectamente), o que desempeñan funciones y servicios públicos, pero solamente con respecto a los fondos o beneficios públicos recibidos o a las funciones y servicios públicos desempeñados."

Se ha señalado, desde la doctrina, que la reglamentación nacional no rige para las Universidades Nacionales en virtud de su carácter autónomo establecido por el art. 75 inc 19 de la CN y por la Ley de Educación Superior (№ 24.521). ${ }^{73}$ Cabe apuntar, que discrepamos con esa opinión en tanto entendemos que el carácter autónomo no redime a las casas de estudio de brindar la información a los ciudadanos que la requieran en tanto integran la organización del Poder Ejecutivo Nacional. Además, más allá de esa disquisición el carácter operativo del derecho fundamental comprometido obliga a permitir su acceso.

Cabe destacar que el caso, “Asociación Derechos Civiles ${ }^{74}$ se admitió la legitimación pasiva de una persona jurídica pública no estatal y señalo que “Dicha

\footnotetext{
${ }^{73}$ BRUNO dOS SANTOS, Marcelo A., FERNÁNDEZ LAMELA, Pablo M., y LOPEZ OLVERA, Miguel Alejandro, “La participación pública y el acceso a la información: herramientas para mejorar la calidad institucional. Comentarios al Decreto 1.172/03", Revista RAP, 2004, esp. acápite II.

74 C.S.J.N., 04/12/2012, "Asociación Derechos Civiles c. EN — PAMI — (dto.1172/03) s/ amparo ley 16.986", A. 917. XLVI.
} 
amplitud supone incluir como sujetos obligados no solamente a los órganos públicos estatales, en todas sus ramas y niveles, locales o nacionales, sino también a empresas del Estado, hospitales, las instituciones privadas o de otra índole que actúan con capacidad estatal o ejercen funciones públicas"

\section{Limitaciones}

\section{Aspectos generales}

Como ocurre con la mayoría de los derechos, el de acceso a la información pública no es de carácter absoluto sino que puede ser reglamentado y restringido por el legislador siempre que sea respetado el valladar de la inalterabilidad y razonabilidad impuesto por el art. 28 de la C.N.

En particular, en virtud del principio de la máxima divulgación —cuyo alcance y acogimiento $^{75}$ ya hemos referenciado-, las limitaciones que se dispongan al derecho de acceso a la información pública deben tener en cuenta tienen las siguientes exigencias: a) Ser declaradas expresamente por ley en sentido material y formal. b) En virtud su carácter excepcional se impone la interpretación restrictiva; ${ }^{76}$ c) Tiene que ser dispuestas por autoridad competente; d) Deben ser necesarias para asegurar necesidades legítimas de las sociedades e instituciones democráticas; ${ }^{77}$ e) Es necesario que se encuentren orientadas a satisfacer un interés público imperativo; f) Encontrarse debidamente fundadas; ${ }^{78}$ g) Cumplir con el recaudo de la proporcionalidad; ${ }^{79}$ h) Asegurar la transparencia. ${ }^{80}$

${ }^{75}$ C.S.J.N., 04/12/2012, "Asociación Derechos Civiles el EN - PAMI - (dto.1172/03) s/ amparo ley 16.986", A. 917. XLVI, considerando 10․ CIDH, "Claude Reyes y otros Vs. Chile". Fondo, Reparaciones y Costas. Sentencia de 19 de septiembre de 2006. Serie C No. 151.

76 GAMERO CASADO, Eduardo y FERNÁNDEZ RAMOS, Severiano, Manual básico de derecho administrativo, Madrid, Tecnos, 2007, 4를., p. 265; GELLI, M., Constitución de la Nación Argentina, op. cit., p. 23; LAVALLE COBO, Dolores, "Un nuevo avance jurisprudencial en el derecho de acceso a la información pública", LA LEY 2005-D, 847, esp. p. 849.

77 En tal sentido ha dicho que "en una sociedad democrática es indispensable que las autoridades estatales se rijan por el principio de máxima divulgación, el cual establece la presunción de que toda información es accesible, sujeto a un sistema restringido de excepciones" y que "Corresponde al Estado demostrar que al establecer restricciones al acceso a la información bajo su control ha cumplido con los anteriores requisitos" (CIDH, "Claude Reyes y otros Vs. Chile". Fondo, Reparaciones y Costas. Sentencia de 19 de septiembre de 2006. Serie C No. 151).

${ }^{78}$ Cfr. BRUNO DOS SANTOS, Marcelo A., FERNÁNDEZ LAMELA, Pablo M., y LOPEZ OLVERA, Miguel Alejandro, "La participación pública y el acceso a la información: herramientas para mejorar la calidad institucional. Comentarios al Decreto 1.172/03", Revista RAP, 2004.

79 En tal sentido ha dicho la CIDH que "Entre varias opciones para alcanzar ese objetivo debe escogerse aquélla que restrinja en menor escala el derecho protegido. Dado este estándar, no es suficiente que se demuestre, por ejemplo, que la ley cumple un propósito útil u oportuno; para que sean compatibles con la Convención las restricciones deben justificarse según objetivos colectivos que, por su importancia, preponderen claramente sobre la necesidad social del pleno goce del derecho que el artículo 13 garantiza y no limiten más de lo estrictamente necesario el derecho proclamado en el artículo 13. Es decir, la restricción debe ser proporcionada al interés que la justifica y ajustarse estrechamente al logro de ese legítimo objetivo" (CIDH, OC 5/85).

80 Cfr. SÁNCHEZ MORON, M., Derecho Administrativo, op. cit., p. 454. 
Cabe destacar que estas circunstancias, como ya hemos analizado, se enmarcan en las exigencias del art. 13.2 de CADH, la Declaración de principios sobre libertad de expresión de la Comisión Interamericana de Derechos Humanos y la OC 5/85 y la jurisprudencia unánime de la $\mathrm{CIDH} .{ }^{81}$

Además, resulta aconsejable que en aquellas hipótesis en que se disponga expresamente la reserva o limitación de una información se lo haga por tiempo determinado y con una duración razonable, aspecto en el que desafortunadamente ha guardado silencio el Decreto 1172/03.

\section{La carga de la prueba}

Es el sujeto pasivo del derecho de acceso a la información pública el que debe acreditar que existe una limitación que impide el conocimiento de la información por parte del ciudadano y justificar su aplicación en el caso concreto teniendo para ello en cuenta el principio de máxima divulgación.

En ese orden de ideas, la Ley Modelo Interamericana sobre acceso a la información establece en el art. 53 lo siguiente: “La carga de la prueba deberá recaer en la autoridad pública a fin demostrar que la información solicitada está sujeta a una de las excepciones contenidas en el Artículo 41. En particular, la autoridad deberá establecer: a) que la excepción es legítima y estrictamente necesaria en una sociedad democrática basada en los estándares y jurisprudencia del sistema interamericano; b) que la divulgación de la información podría causar un daño sustancial a un interés protegido por esta Ley; y c) que la probabilidad y el grado de dicho daño es superior al interés público en la divulgación de la información".

\section{Causales}

En lo concerniente a las causales que autorizan a limitar el derecho de acceso, éstas pueden agruparse entre las que obedecen a motivos de bienestar general y aquellas que tienden a proteger derechos individuales.

Así, en razón del interés público comprometido en el caso puede restringirse el acceso a aquella información público cuyo conocimiento por parte de los ciudadanos pueda comprometer: a) La seguridad o la defensa nacional;82 b) El secreto de Estado;

\footnotetext{
81 Caso "La Última Tentación de Cristo" (Olmedo Bustos y otros) Vs. Chile". Fondo, Reparaciones y Costas. Sentencia de 5 de febrero de 2001. Serie C No. 73; Caso "Ivcher Bronstein Vs. Perú. Fondo", Reparaciones y Costas. Sentencia de 6 de febrero de 2001. Serie C No. 74. Caso “Herrera Ulloa Vs. Costa Rica”. Excepciones Preliminares, Fondo, Reparaciones y Costas. Sentencia de 2 de julio de 2004. Serie C No. 107; Caso "Ricardo Canese Vs. Paraguay". Fondo, Reparaciones y Costas. Sentencia de 31 de agosto de 2004. Serie C No. 111, entre muchos otros.

82 BASTERRA M., El derecho fundamental de acceso a la información pública, op. cit., p. 371.
} 
c) La investigación de delitos o la salud pública; ${ }^{33}$ d) Las estrategias de defensa en juicio de la administración; 84 e) La confidencialidad en el manejo de negociaciones internacionales; f) La política exterior. ${ }^{85} \mathrm{~g}$ ) La eficacia de la administración, por ejemplo, si va a disponer una investigación. h) Los actos políticos; ${ }^{86}$ i) El desenvolvimiento del sistema bancario. j) Los mecanismos de control público.

Asimismo, como vimos, existen restricciones al acceso a la información pública a causa del interés privado lo que permite vedar el conocimiento de aquella tenga la potencialidad para comprometer: a) El secreto profesional, empresarial, científico, sacerdotal o comercial; $; 8$ b) El derecho a la intimidad; $; 8$ c) La confidencialidad de un dato; ${ }^{89}$ d) El derecho a la vida o la integridad física de una persona; ${ }^{90}$ e) Patentes, derechos de autor y secreto comercial. ${ }^{91}$

En definitiva, tanto en las limitaciones que están vinculadas al resguardo del bien común como las que protegen al interés privado, nos encontramos frente a la colisión de derechos que en caso de ser necesario deberá ser ponderado o armonizados por el juez competente a los fines de dilucidar si puede accederse o no la información peticionada.

En el primer supuesto, desde nuestra perspectiva, se enfrenta el derecho de cualquier persona a conocer la información pública y el bien común comprometido en la limitación o reserva de la información. Aquí, parece apropiado inclinar la balanza en caso de duda a favor del peticionante y, por consiguiente, permitirle el acceso a la información que solicita.

En cambio, consideramos que cuando el acceso a la información tiene la potencialidad para violentar derechos de particulares como la intimidad, la salud, la vida, etc., la balanza debe inclinarse en contra del acceso a la información, siempre en caso de dudas.

\footnotetext{
83 Idem, p. 172.

${ }^{84}$ Cfr. art 16 inc. f) Decreto 1172/03.

85 Cfr. art 16 inc. a) Decreto $1172 / 03$.

86 SÁNCHEZ MORON, M., Derecho administrativo, op. cit., p. 458.

87 Art. 116 inc. g.

${ }^{88}$ Así, lo establece, por ejemplo, el art. 3o de la Ley 8803 de la Provincia de Córdoba.

89 En este caso no se podrá acceder a aquella información que se encuentre en un registro pero que por vía de habeas data ha sido sustraído de su conocimiento general. Sobre el punto vid. BASTERRA, Marcela, "El habeas data" en AA.VV. Derecho procesal constitucional, (Manili, Pablo L., coord.), Buenos Aires, Edit. Universidad, 2005, p. 151.

90 Cfr. art 16 inc. j) Decreto 1172/03.

91 Ver. art. 41.3 de la Ley modelo interamericana sobre acceso a la información (Documento presentado por el Grupo de Expertos sobre Acceso a la Información coordinado por el Departamento de Derecho Internacional, de la Secretaría de Asuntos Jurídicos, de conformidad con la resolución AG/RES. 2514 —XXXIX-0/09— de la Asamblea General de la Organización de Estados Americanos).
} 


\section{XIIII Mecanismos de protección}

Para que el derecho al acceso a la información pública adquiera eficacia resulta preciso que se instrumenten los conductos administrativos y jurisdiccionales que permitan hacer exigible ese derecho.

En el ámbito nacional, el Decreto 1172/03 establece que en caso de que la información sea denegada la vía idónea para obligar a la administración a proveerla es el art. 28 de la Ley 19.549, esto es el amparo por mora.

Esa premisa nos lleva a plantearnos el interrogante de si estamos frente a un amparo por mora "especial". Creemos que la respuesta es negativa dado que el Decreto 1172/03 no hace alusión al "amparo por mora" sino al mecanismo previsto en el art. 28 de la LNPA., lo que implica que estamos frente al mismo supuesto.92

A los efectos de poder determinar su idoneidad como medio de tutela, debe tenerse presente que el objeto del amparo por mora es el mandato de un pronto despacho a la administración para que se expida o de curso a las actuaciones administrativas, ${ }^{93}$ es decir una obligación de hacer, con lo cual la orden de brindar la información que se requiere al Poder Judicial constituye una obligación de dar. A partir de ello, debemos concluir que ese mecanismo resulta inapropiado para encausar ese tipo de pretensiones.

En esa línea interpretativa se falló la causa "Asociación por los Derechos Civiles", ${ }^{94}$ "que se trataba de una demanda de amparo promovida frente a la denegatoria expresa al pedido de acceso a la información realizado ante Jefe de Gabinete de Ministros de la Nación a los fines de conocer el contenido de ciertas actas del directorio de Radio y Televisión Argentina Sociedad del Estado. Allí, la Cámara en lo contencioso administrativo federal estimó que la vía del art. 28 de la L.N.P.A. no tenía el alcance de exigir a la Administración que se pronuncie en un sentido o en otro, sino tan sólo que se expida, en tanto su estrecho ámbito de conocimiento no permite controlar la legalidad de la respuesta brindada, que debe eventualmente ser cuestionada por los cauces pertinentes.

De la misma manera se había pronunciado dicho tribunal in re "Taboada Mussi"95 al sentenciar que: "Con el amparo por mora no puede perseguirse otra cosa

\footnotetext{
92 Como se sabe, también se puede pedir el acceso a información que se halle en manos de particulares que se encuentren comprendidos como sujetos pasivos por el Decreto 1172/03. En ese caso, según la solución que se propone normativamente, esto es la utilización del amparo por mora, sería inadecuada dado que este remedio de pronto despacho judicial solo puede utilizarse en contra de autoridades públicas, y en la mayoría de los casos se requiere la titularidad de un derecho subjetivo o de un interés legítimo para su procedencia.

${ }^{93}$ Cfr. SAMMARTINO, Patricio M.E., "El amparo por mora de la administración" en AA.VV., Derecho procesal constitucional, (Pablo. L. Manili Dir.), Buenos Aires, Ed. Universidad, 2005, p. 100; IVANEGA, Miriam M., "EI amparo por mora", en A.A.V.V., Amparo, medidas cautelares y otros procesos urgentes en la justicia administrativa, obra conjunta, Juan Carlos Cassagne (Director), Buenos Aires, Lexis Nexis, 2007, p. 93.

94 Sentencia del 10/05/2011.

95 Conf., Sala II, 03/06/2008, “Taboada Mussi Mirta Fernanda c/TBA SA (Trenes de Buenos Aires SA) S/ Amparo por mora”, causa № $1243 / 2007$.
} 
que no sea obligar a la administración a que emita un dictamen o una resolución de mero trámite o de fondo. El propósito perseguido no puede ser otro que la obtención de una orden de pronto despacho y tal pretensión resulta objetivamente satisfecha más allá de que se acceda al reclamo del fondo que la sustenta". ${ }^{96}$

A su vez, debe quedar en claro que esa norma del Decreto 1172/03 no se refiere a los supuestos en donde la negativa de brindar la información es expresa y clara, con lo cual, en esos casos, la vía del amparo por mora no sería tampoco la correspondiente.

Entonces, si la respuesta es que ese remedio no resulta idóneo para la tutela del DAIP —en ambos supuestos tratados_- debemos indagarnos sobre cuál es la vía que debe utilizarse. Esa problemática expuesta ha hecho que en la práctica se acuda a otros instrumentos tales como la diligencia preliminar, la demanda autónoma de información y la acción de amparo.

Con relación a la primera, su regulación normativa se halla en el art. 323 del Código procesal Civil y Comercial de la Nación y tiene por finalidad asegurar a las partes la oportunidad de plantear sus pretensiones y excepciones o defensas. ${ }^{97}$

Al respecto, se evidencia el problema acerca si la enunciación contenida en dicha cláusula es o no taxativa. Quienes se inclinan por la negativa sostienen que el juez puede a su criterio admitir otras distintas a las contempladas por la norma "en tanto y en cuanto ello resulte o aparezca como imprescindible para poder emplazar correcta y útilmente la demandada o su contestación". ${ }^{98}$ Ello, siempre teniendo en consideración que la procedencia de la diligencia preliminar está subordinada al futuro inicio de un juicio de conocimiento y esencialmente tiene por objeto asegurar o conservar pruebas.

También, puede pensarse en la procedencia de una demanda autónoma de información, sea que se utilice la vía ordinaria o abreviada. A esos efectos, cabe traer a colación el fallo de la Sala IV de la Cámara en lo Contencioso-administrativo federal en la causa "Asociación del personal legislativo c/ Estado nacional - $\mathrm{H}$. Congreso de la Nación - H. Senado-ley $23.551 \mathrm{~s} /$ diligencia preliminar". ${ }^{99}$ Allí, si bien el tribunal entendió que la solicitud no encuadraba como diligencia preliminar en la medida en que no cumplía los requisitos que ella presupone, no obstante entendió en aplicación del principio iura novit curia, que debía ser encuadrada como demanda autónoma fundada en el derecho de acceso a la información pública reconocida en

\footnotetext{
96 Ibidem.

97 Conf., KIELMANOVICH, Jorge L., Código Procesal Civil y Comercial de la Nación, Buenos Aires, Lexis Nexis, 3ra ed., T. I, p. 618.

98 Ídem, ps. 618/619.

99 Sentencia del 3/06/2004, Revista de derecho administrativo № 52, Abeledo Perrot, ps. 286 y ss.
} 
los arts. 1, 33, 41 y 42 de la Constitución Nacional. ${ }^{100}$ Es decir, el tribunal reencuadró la acción con fundamento en la autosuficiencia del pedido de información y en la ausencia de vinculación con la promoción de un concreto proceso futuro.

En cuanto a la utilización de la acción de amparo, en el aludido fallo "ADC", ${ }^{101}$ se entiende que ese es el cauce de tutela del DAIP. Si bien, ese remedio puede parecer de manera apriorística la mejor solución no podemos soslayar que la utilización de esa vía puede provocar discusiones que vayan en desmedro de cauce escogido por el requirente de la información. Nos referimos a la cuestión del plazo de caducidad para promover la acción, de la existencia de vías judiciales más idóneas, de la necesidad de mayor debate y prueba, la posibilidad de rechazo in limine, etc.

En un caso en donde diputado nacional había promovido acción de amparo con el objeto de que se le ordene a la Inspección General de Justicia la entrega de información respecto de la constitución y operatoria de determinadas sociedades relacionadas con una imprenta privada que se dedicaba a la impresión de billetes el tribunal de alzada consideró que el hecho de que el art. 14 del decreto $1172 / 2003$ indique el amparo por mora como vía para acceder a información pública ante el silencio de la Administración no excluye la posibilidad de que el interesado inicie, el amparo previsto en la ley 16.986, cuyos requisitos de admisión y procedencia resultan más estrictos, en tanto, una decisión contraria, implicaría un exceso reglamentario. ${ }^{102}$

Podrá pensarse, también, que existiendo una vía judicial especifica fijada por el ordenamiento aplicable a la especie (amparo por mora) el amparo genérico queda desplazado como mecanismo de tutela del derecho a la información pública en tanto el cauce del art. 43 de la CN queda excluido por la existencia de una vía judicial más idónea.

A pesar de ello, la jurisprudencia sigue entendiendo que es el amparo constitucional la vía correcta y útil para lograr el acceso a la información pública, en tanto existe una afectación de derechos constitucionales del más alto rango del interesado. ${ }^{103}$

\footnotetext{
100 En efecto, sostuvo en el considerando IV que no se encontraban reunidas las exigencias para la excepcional vía procesal intentada y que “... resulta que la parte actora persigue tomar conocimiento de los "Decretos de Presidencia, con las designaciones de personal de ambas plantas (transitoria y permanente) y [...] las modificaciones realizadas en las estructuras del Honorable Senado, por el período del año en curso (2002), promociones, subrogancias, designaciones extraescalafonarias y modificaciones de la estructura orgánica". Ídem, p. 286.

${ }^{101}$ C.S.J.N., 04/12/2012, “Asociación Derechos Civiles c. EN - PAMI - (dto.1172/03) s/ amparo ley 16.986", A. 917. XLVI.

${ }^{102}$ Cámara Nacional de Apelaciones en lo Contencioso administrativo Federal, sala V, 19/06/2013, “Gil Lavedra, Ricardo Rodolfo c. EN-M de Justicia y DDHH”, LA LEY 2013-E, p. 156.

${ }^{103}$ Cam. Nac. Fed. Cont. Adm, Sala III, 27/05/2005, “Centro de Implementación de Políticas Públicas E. y C. y otro c/ Honorable Cámara de Senadores del Congreso de la Nación"; Idem, 17/12/97, "Tiscornia Sofía y otro c/ E.N. (M. del Interior) y otro s/ amparo ley $16.986 "$.
} 


\section{La información pública positiva}

En primer lugar, debe tenerse presente que cuando nos referimos a "información pública positiva" hacemos alusión a la obligación estatal de poner en conocimiento de la ciudadanía — por motu proprio o por imperio legal— la información pública.

Cabe destacar, que este novedoso enfoque del DAIP, que ya está siendo utilizado en el derecho comparado, acrecienta el papel de esta herramienta como cauce de participación ciudadana en los asuntos públicos y como mecanismo para lograr la trasparencia gubernamental.

a) Aspectos generales: En estos casos, la publicidad de la información estatal ya no depende de la inquietud del interesado sino que es producto de un mandato normativo o de la propia decisión estatal.

Así, los Estados que procuran alcanzar mayores niveles de transparencia y reducir la corrupción adoptan conductas proactivas destinadas a poner en conocimiento de los habitantes la actividad estatal. Sino son los propios órganos legisferantes quienes consagran normativamente esa obligación y cuál es la información que debe darse a conocer así como su periodicidad. Es muy importante, en ambos supuestos, que la información nueva se publicite con cierta frecuencia y que se actualice la ya existente.

Esas normas que regulan la obligación estatal de poner en conocimiento de la ciudadanía cierta información acuden a la noción de "obligación mínima" cuyo contenido será establecido por cada organismo estatal o supranacional, según corresponda. A los fines de su determinación, debe acudirse a otra noción que es la de "relevancia" que aparece, de ese modo, como el factor determinante del deber del Estado de hacer pública la información. Como podrá advertirse, se trata de un concepto jurídico indeterminado ${ }^{104}$ que deja sujeto a la valoración de la administración pública la determinación de enunciado, ${ }^{105}$ con el consiguiente control judicial. ${ }^{106}$

De esta manera, se recomienda que la autoridad administrativa por su propia iniciativa y cuando lo considere apropiado, adopte las medidas necesarias para poner en conocimiento de la ciudadanía la información que sea "de interés" o "relevante" para promover la trasparencia y eficacia de la administración ${ }^{107}$ y que se asegure

\footnotetext{
${ }^{104}$ Consisten en definiciones genéricas efectuados por el ordenamiento administrativo que para aplicarse a un caso concreto requieren ser interpretadas por el Poder Judicial dado que muchas veces se refieren a realidades extrajurídicas no precisadas en norma alguna (Cfr. SÁNCHEZ MORON, M., Derecho administrativo, op. cit, p. 92).

${ }^{105}$ Cfr. COMADIRA, Julio R., “La actividad discrecional de la Administración Pública. Justa medida del control judicial", E.D. 186:600.

${ }^{106}$ En esos casos, la labor del juez estará destinada a comprobar si la valoración efectuada por el poder administrador se corresponde con lo establecido por la norma y advertir — de ese modo— si la administración se ha equivocado o no en la aplicación del concepto al caso concreto.

${ }^{107}$ Cfr. GUICHOT, E., op. cit., p. 288.
} 
que la misma sea accesible y comprensible. ${ }^{108}$ Como podrá advertirse, esta nueva modalidad de acceder a la información permite, además, reducir la conflictividad que presenta el pedido de la información por la parte interesada.

La información pública positiva se asienta en dos pilares básicos. Por un lado, en la capacitación a los empleados estatales para el manejo de la información y sus diversos mecanismos de acceso y en la consiguiente responsabilidad de los funcionarios públicos que tienen a cargo difundir la información. Por el otro, en la creación de oficinas estatales que hagan un seguimiento de la labor de las autoridades públicas y un control de la calidad, completitud y veracidad de la información que se da a conocer.

b) Medios: Es importante tener en cuenta que este concepto de información pública positiva exige no solo la divulgación de la información sino también de los medios para acceder a ella adquiriendo relevancia a esos efectos el uso e implementación por parte de las administraciones públicas de las nuevas tecnologías a los fines de facilitar el acceso y el ejercicio de este derecho constitucional.

Como vimos, el Estado deberá ir colocando gradualmente la información pública en registros y se permitirá su acceso a través de la Internet o la difundirá a través de medios electrónicos. De este modo, la tecnología aparece como un instrumento para acercar la administración al ciudadano y para permitir el crecimiento de la transparencia. También, puede utilizarse el Boletín Oficial o los medios de comunicación pública.

c) El derecho supranacional: La cuestión que venimos analizando, incluso, ha sido regulada en el plano internacional por la Convención de Naciones Unidas contra la corrupción, la cual ha sido ratificada por nuestro país, lo que hace aplicables sus preceptos habida cuenta su carácter operativo, ${ }^{109}$ salvo en materia penal. ${ }^{110}$

Dicho instrumento prevé en el art. 10 que "Habida cuenta de la necesidad de combatir la corrupción, cada Estado Parte, de conformidad con los principios fundamentales de su derecho interno, adoptará las medidas que sean necesarias para aumentar la transparencia en su administración pública, incluso en lo relativo a su organización, funcionamiento y procesos de adopción de decisiones, cuando proceda. Esas medidas podrán incluir, entre otras cosas: a) La instauración de procedimientos o reglamentaciones que permitan al público en general obtener, cuando proceda, información sobre la organización, el funcionamiento y los procesos de adopción de decisiones de su administración pública y, con el debido respeto a la protección de la intimidad y de los datos personales, sobre las decisiones y actos jurídicos

\footnotetext{
${ }^{108}$ VALLEFIN, Carlos A., El acceso a la información pública. Una introducción, Buenos Aires, Ad Hoc, 2009, p. 29. ${ }^{109}$ Para Manfroni la operatividad no es inmediata en materia penal (MANFRONI, Carlos A., La convención interamericana contra la corrupción, anotada y comentada, Buenos Aires, Abeledo Perrot, 2001, 2a Ed. act. p. 112).

${ }^{110}$ Cf. GORDILLO, Agustín, Tratado de Derecho administrativo, Buenos Aires, Fundación de Derecho administrativo, 5a Ed. T. I, p. XVI, 19.
} 
que incumban al público; b) La simplificación de los procedimientos administrativos, cuando proceda, a fin de facilitar el acceso del público a las autoridades encargadas de la adopción de decisiones; y c) La publicación de información, lo que podrá incluir informes periódicos sobre los riesgos de corrupción en su administración pública".

Por otra parte, el art. 13 dispone que "Cada Estado Parte adoptará medidas adecuadas, dentro de los medios de que disponga y de conformidad con los principios fundamentales de su derecho interno, para fomentar la participación activa de personas y grupos que no pertenezcan al sector público, como la sociedad civil, las organizaciones no gubernamentales y las organizaciones con base en la comunidad, en la prevención y la lucha contra la corrupción, y para sensibilizar a la opinión pública con respecto a la existencia, las causas y la gravedad de la corrupción, así como a la amenaza que ésta representa. Esa participación debería reforzarse con medidas como las siguientes: a) Aumentar la transparencia y promover la contribución de la ciudadanía a los procesos de adopción de decisiones; b) Garantizar el acceso eficaz del público a la información; c) Realizar actividades de información pública para fomentar la intransigencia con la corrupción, así como programas de educación pública, incluidos programas escolares y universitarios; d) Respetar, promover y proteger la libertad de buscar, recibir, publicar y difundir información relativa a la corrupción".

d) El derecho comparado: Cabe destacar que esta modalidad, que todavía no ha sido receptada en el ordenamiento federal argentino ha tenido interesantes resultados en el derecho comunitario europeo ${ }^{111} \mathrm{y}$ en el ámbito del derecho comparado. ${ }^{112}$

En tal sentido, el art. 5 de la Ley 18.381 de Uruguay señala que "Los sujetos obligados deberán prever la adecuada organización, sistematización y disponibilidad de la información en su poder, asegurando un amplio y fácil acceso a los interesados. Los organismos públicos, sean o no estatales, deberán difundir en forma permanente, a través de sus sitios web u otros medios que el órgano de control determine, la siguiente información mínima: a) Su estructura orgánica; b) Las facultades de cada unidad administrativa; c) La estructura de remuneraciones por categoría escalafonaria, funciones de los cargos y sistema de compensación; d) Información sobre presupuesto asignado, su ejecución, con los resultados de las auditorías que en cada caso corresponda; e) Concesiones, licitaciones, permisos o autorizaciones otorgadas, especificando los titulares o beneficiarios de éstos; f) Toda información estadística de interés general, de acuerdo a los fines de cada organismo y

\footnotetext{
111 Vgr. En el ámbito de la Unión Europea la Recomendación del Comité de Ministros del 21 de febrero de 2002 sobre acceso a la información oficial.

112 Vgr. Canadá (Acces to Information act) (Cfr. BASTERRA, M., El derecho fundamental de acceso a la información pública, op. cit., p. 215).
} 
g) Mecanismos de participación ciudadana, en especial domicilio y unidad a la que deben dirigirse las solicitudes para obtener información".

Por su parte, en Panamá el art. 9 de la Ley de Transparencia en la Gestión Pública y Habeas Data (Ley 6/2002) establece que "En atención al principio de publicidad, las instituciones del Estado están obligadas a tener disponible en forma impresa, en sus respectivos sitios en Internet y a publicar periódicamente, información actualizada respecto de los temas, documentos y políticas que a continuación se detallan: 1 . El reglamento interno actualizado de la institución. 2. Las políticas generales de la institución, que formen parte de su plan estratégico. 3. Los manuales de procedimientos internos de la institución. 4. La descripción de la estructura organizativa de la institución. 5. La ubicación de documentos por categorías, registros y archivos de la institución, y el funcionario responsable de éstos. 6. La descripción de los formularios y reglas de procedimiento para obtener información de la institución y dónde pueden ser obtenidos. Las instituciones públicas que tienen páginas electrónicas, además de los boletines, estarán obligadas a publicar a través de Internet la información que obliga la presente Ley. La Contraloría General de la República deberá publicar un informe sobre la ejecución presupuestaria, a más tardar dentro de los treinta días posteriores a dicha ejecución. El Ministerio de Economía y Finanzas deberá publicar un informe sobre la ejecución presupuestaria, a más tardar dentro de los treinta días posteriores a tal ejecución".

Por su parte, la Constitución de México en su art. 6으, luego de consagrar el derecho de acceso a la información y proteger su ejercicio, señala en el punto $\checkmark$ que "Los sujetos obligados deberán preservar sus documentos en archivos administrativos actualizados y publicarán a través de los medios electrónicos disponibles, la información completa y actualizada sobre sus indicadores de gestión y el ejercicio de los recursos públicos".

e) Objeto: Mas allá de lo que se prevea en la regulación específica y de lo que se derive de los tratados internacionales a los que hicimos alusión más arriba, entre la información que debe ponerse en conocimiento de los ciudadanos se destaca la siguiente:

1. La organización y distribución de competencias de cada repartición pública, su estructura jerárquica, su domicilio y demás datos que permitan su individualización;

2. La reglamentación interna de cada entidad;

3. La descripción de los formularios, del procedimiento de acceso a la información y las herramientas que pueden utilizarse en caso denegatoria total o parcial;

4. Clase de archivos que posee cada organismo, de modo de facilitar el acceso;

5. Los mecanismos y procedimientos de adopción de decisiones públicas; 
6. Los datos personales que permitan identificar a los funcionarios que integran cada repartición;

7. Las competencias de cada autoridad;

8. Régimen de funcionamiento;

9. Asignación presupuestaria;

10. Concesiones de obras y servicios, habilitaciones concedidas, permisos otorgados;

11. Régimen de contrataciones públicas;

12. Régimen disciplinario.

En este orden de ideas, la Ley Modelo Interamericana sobre acceso a la información establece en el art. 9 que “(1) Toda autoridad pública deberá adoptar y diseminar de manera amplia, incluyendo la publicación a través de su página de Internet, un esquema de publicación aprobado por la Comisión de Información dentro de [seis] meses de: a) la entrada en vigor de la presente Ley; o b) del establecimiento de la autoridad pública en cuestión. (2) El Esquema de Publicación deberá establecer: a) las clases de documentos que la autoridad publicará de manera proactiva; y b) la forma en la cual publicará dichos documentos. (3) Al adoptar un Esquema de Publicación, una autoridad pública deberá tomar en consideración el interés público: a) de permitir el acceso a la información que está en su posesión; y b) de divulgar información de manera proactiva a los efectos de minimizar la necesidad de que los individuos presenten solicitudes de información. (4) Toda autoridad pública deberá publicar información de conformidad con su esquema de publicación.

Asimismo, en el art. 12 indica que "(1) Las clases de información clave sujetas a diseminación de manera proactiva por una autoridad pública son las siguientes: a) la descripción de su estructura orgánica, de sus funciones y deberes, de la ubicación de sus departamentos y organismos, de sus horas de atención al público y de los nombres de sus funcionarios; b) las calificaciones y salarios de los altos funcionarios; c) todo mecanismo interno y externo de supervisión, de reportes y de monitoreo de la autoridad pública, incluyendo sus planes estratégicos, códigos de gobernabilidad empresarial y principales indicadores de desempeño, incluidos los informes de auditoría; d) su presupuesto y planes de gasto público del año fiscal en curso y de años anteriores, y los informes anuales sobre la manera en que se ejecuta el presupuesto; e) sus procedimientos, lineamientos, políticas en materia de adquisiciones, contratos otorgados y datos para la ejecución y seguimiento del desempeño de contratos; f) las escalas salariales, incluyendo todos los componentes y subcomponentes del salario total, correspondientes a todas las categorías de funcionarios y consultores que trabajan en la autoridad pública (actualizando la información en cada oportunidad que se realicen reclasificaciones de puestos); g) detalles pertinentes sobre todo servicio que brinde directamente al público, 
incluyendo normas, cartas y protocolos de atención al cliente; h) todo mecanismo de presentación directa de solicitudes o denuncias a disposición del público en relación con acciones $u$ omisiones de esa autoridad pública, junto con un resumen de toda solicitud, denuncia u otra acción directa de personas y la respuesta de ese órgano; i) una descripción de las facultades y deberes de sus funcionarios principales, y los procedimientos que se siguen para tomar decisiones; j) todas las leyes, reglamentos, resoluciones, políticas, lineamientos o manuales, $u$ otros documentos que contengan interpretaciones, prácticas o precedentes sobre el desempeño del órgano en el cumplimiento de sus funciones que afectan al público en general; k) todo mecanismo o procedimiento por medio del cual el público pueda presentar peticiones, o de alguna otra manera incidir en la formulación de la política o el ejercicio de las facultades de esa autoridad pública; I) una guía sencilla que contenga información adecuada sobre sus sistemas de mantenimiento de documentos, los tipos y formas de información que obran en su poder, las categorías de información que publica y los procedimientos que deben seguirse para formular una solicitud de información y una apelación interna; m) un Registro de Solicitudes y divulgaciones, de conformidad con el Artículo 18, que contenga una lista de las solicitudes recibidas y los documentos divulgados de conformidad con la presente Ley, los que deberán estar automáticamente disponibles, así como un Registro de Activos de Información, de conformidad con el Artículo 17; n) una lista completa de los subsidios otorgados por la autoridad pública; o) aquella información que sea solicitada con frecuencia; у p) cualquier información adicional que la autoridad pública considere oportuno publicar. (2) Los esquemas de publicación adoptados por las autoridades públicas deberán cubrir todas las clases de información clave establecidas en el Artículo 12 (1) dentro de un plazo de [siete] años contados a partir de la adopción del primer esquema de publicación de esa autoridad pública, de conformidad con el Artículo 9 (1). (3) La autoridad pública deberá crear y archivar en forma anual una imagen digital de su página Web que contenga toda la información requerida por el esquema de publicación.

Transparency as Public Policy against Corruption: Contributions on the Regulation of the Right of Access to Public Information

Abstract: The intention of this paper is to analyze the link between corruption, transparency and put shoulder the main guidelines that should be regulating access to public information.

Key words: Corruption. Transparency. Public Information. 
Informação bibliográfica deste texto, conforme a NBR 6023:2002 da Associação Brasileira de Normas Técnicas (ABNT):

BUTELER, Alfonso. La transparencia como política pública contra la corrupción: aportes sobre la regulación de derecho de acceso a la información pública. A\&C Revista de Direito Administrativo \& Constitucional, Belo Horizonte, ano 14, n. 58, p. 61-106, out./dez. 2014.

Recebido em: 05.01.2014 Aprovado em: 08.09.2014 